Mariana Lisboa Maximo

\title{
Evaluating the Design of a Performance Measurement System for Downstream Logistics in an Energy Company
}

Thesis presented to the Programa de Pós-Graduação em Engenharia de Produção of the Departamento de Engenharia Industrial, PUC-Rio, as partial fulfillment of the requirements for the degree of Mestre em Engenharia de Produção - opção profissional.

Advisor: Prof. Luiz Felipe Roris Rodriguez Scavarda do Carmo 
Mariana Lisboa Maximo

\section{Evaluating the Design of a Performance Measurement System for Downstream Logistics in an Energy Company}

Thesis presented to the Programa de Pós-Graduação em Engenharia de Produção of the Departamento de Engenharia Industrial, PUC-Rio, as partial fulfillment of the requirements for the degree of Mestre em Engenharia de Produção - opção profissional.

Prof. Luiz Felipe Roris Rodriguez Scavarda do Carmo

Advisor

Departamento de Engenharia Industrial - PUC-Rio

Prof. Bernd Hellingrath

University of Münster

Prof. Roberto Antônio Martins Universidade Federal de São Carlos - UFSCar

Prof. Adriana Leiras

Departamento de Engenharia Industrial - PUC-Rio

Prof. José Eugênio Leal

Coordinator of the Centro Técnico Científico - PUC-Rio

Rio de Janeiro, May 28th, 2013 
All rights reserved.

\section{Mariana Lisboa Maximo}

Mariana Lisboa Maximo graduated in Industrial Engineering at Universidade Federal do Rio de Janeiro in 2006 and attended one year of specialization in Logistics at École Centrale de Paris. Since 2007 she works at Petrobras Downstream Logistics Division, where she integrates a team of operational performance analysts.

Bibliographic data

Maximo, Mariana Lisboa

Evaluating the design of a performance measurement system for downstream logistics in an energy company / Mariana Lisboa Maximo; advisor: Luiz Felipe Roris Rodriguez Scavarda do Carmo. - 2013.

94 f. : il. (color.) ; $30 \mathrm{~cm}$

Dissertação (mestrado) - Pontifícia Universidade Católica do Rio de Janeiro, Departamento de Engenharia Industrial, 2013.

Inclui bibliografia

1. Engenharia Industrial - Teses. 2. Sistema de medição de desempenho. 3. Avaliação de desempenho. 4. Indicadores. I. Carmo, Luiz Felipe Roris Rodriguez Scavarda do. II. Pontifícia Universidade Católica do Rio de Janeiro. Departamento de Engenharia Industrial. III. Título.

CDD: 658.5 
To my parents, my safe harbor.

To my husband, my source of encouragement. 


\section{Acknowledgments}

To God, who gave me life, a beautiful family, love, hope, friends and have always guided me in the way of good.

To my parents, who have always done the best efforts to provide me an excellent education and teach me in the virtues necessary for life.

To my advisor, Luiz Felipe, who devoted so much time to my learning and was tireless in demanding my best in this study.

To all my friends and my Petrobras colleagues, especially AO team, who encouraged me in this important journey of knowledge.

The author of this dissertation acknowledges the professors who kindly accepted the invitation to collaborate with their experience for the evaluation of this study and also acknowledges CAPES and DAAD for their support in the PROBAL project entitled "Development of a Maturity Measurement Framework for Supply Chain Flexibility". 


\section{Abstract}

Maximo, Mariana Lisboa; Carmo, Luiz Felipe Roris Rodriguez Scavarda do (Advisor). Evaluating the Design of a Performance Measurement System for Downstream Logistics in an Energy Company. Rio de Janeiro, 2013. 94p. MSc. Dissertation - Departamento de Engenharia Industrial, Pontifícia Universidade Católica do Rio de Janeiro.

Performance Measurement System (PMS) is already a consecrated tendency among companies concerned with an entire and solid set of metrics, process and system to support performance assessment efficiently. The design of a PMS requires deep evaluation of the current measurement situation used, concrete managers' engagement and clarity in the objectives and goals to be achieved with the new system. There is little research evidence that illustrates the transition between design and implementation phases of a PMS. Within this context, this dissertation presents a case study carried out at Petrobras concerning the design of a PMS for its Downstream Logistics Division and the preparation of its implementation. The value of applying some practices during design phase in order to prevent implementation problems is considered in the case. Throughout the initiative, conceptual ideas generated by the design team needed to be tested and sometimes adapted in order to provide a better implementation. As consequence, the transition between design and implementation phases revealed to be an important and delicate moment, directly responsible for the success of the PMS implementation. If definitions established and decisions taken during design phase are not properly addressed, it runs the risk of loosing the main purposes of the new system; this particular aspect is discussed in the dissertation regarding the case study observations.

\section{Keywords}

Performance Measurement System; Performance Measurement; Performance Metrics. 


\section{Resumo}

Maximo, Mariana Lisboa; Carmo, Luiz Felipe Roris Rodriguez Scavarda do. Análise do desenho de um sistema de medição de desempenho para a logística de abastecimento de uma empresa de energia. Rio de Janeiro, 2013. 94p. Dissertação de Mestrado - Departamento de Engenharia Industrial, Pontifícia Universidade Católica do Rio de Janeiro.

São muitas as definições para Sistema de Medição de Desempenho (SMD) na literatura acadêmica, o que demonstra a relevância do tema para os dias atuais. Várias empresas já adotaram um SMD visando monitorar de forma mais eficiente o desdobramento da sua estratégia a partir de indicadores de desempenho, assim como a elaboração de ações corretivas quando da identificação de desvios. O SMD, segundo definição utilizada na dissertação, é um sistema (software, métricas, processo) que executa a medição de desempenho de forma mais consistente e eficiente. Algumas características de um bom SMD: possui indicadores financeiros e não financeiros; auxilia na previsão do que poderá acontecer ao negócio e/ou na constatação do que ocorreu e constrói uma sistemática para avaliação das métricas, assegurando que elas estimulem ações corretivas. Conceitualmente o desenvolvimento de um SMD pode ser dividido em fases, a saber: (1) design (ou construção), (2) implantação, (3) uso e revisão. Todas as fases são igualmente importantes, embora haja mais trabalhos publicados relativos à fase de design. Durante a construção de um SMD, uma das principais dificuldades é a escolha das métricas para compor o sistema. Essa escolha é chave para que os indicadores reflitam de forma adequada a natureza do negócio e possam orientar um trabalho mais assertivo dentro da organização. $\mathrm{O}$ desenho de um processo colaborativo e a escolha de uma boa ferramenta tecnológica para auxiliar na avaliação do desempenho também são elementos importantes para o êxito do novo sistema. A diretoria de Logística do Abastecimento da Petrobras percebeu a necessidade de implantação de um SMD para medir seu desempenho de maneira mais integrada, completa e eficaz. Anteriormente ao estudo apresentado nessa dissertação, a diretoria realizava sua avaliação de desempenho de forma muito restrita, e com o uso de indicadores que calculavam simples 
comparações entre realizado e planejado. A medição de desempenho da época avaliava apenas parte das operações realizadas e não contava com o patrocínio dos gerentes mais altos. Neste contexto, o objetivo desta dissertação é o de analisar o desenho de um SMD na operação de logística de abastecimento da Petrobras dando enfoque na transição entre o desenho e a implantação do sistema. A partir desta pesquisa, foi feito o primeiro diagnóstico de como o desempenho era medido, definiu-se um plano de ação com 29 meses de trabalho para que o SMD estivesse ativo: indicadores prontos, sistema de informação em uso e processo de avaliação estabelecido. Durante o período do projeto foram necessários alguns replanejamentos de escopo por conta de atrasos ou por novas decisões tomadas (como, por exemplo, a decisão de criar um protótipo). Foram seguidos três passos principais no desenrolar do estudo de caso: (1) avaliação do contexto, coleta de dados e planejamento da ação, (2) a fase de design e seu desenvolvimento e (3) avaliação final. Revisão bibliográfica, entrevistas e seminários foram adotados como ferramentas para a pesquisa. Para a construção do SMD foi necessária uma completa avaliação das métricas existentes, sistemas e dados disponíveis para realização do diagnóstico do estado inicial e o planejamento das ações futuras. A partir desse planejamento foram discriminadas as etapas de escolha das métricas e desenho do processo, de pesquisa da solução tecnológica, implantação e avaliação. O projeto originou um conjunto de lições aprendidas para futuros sistemas, sendo uma delas, e principal, as vantagens de se considerar determinadas práticas durante a etapa de design que permitem tratamentos antecipados de possíveis problemas da fase de implantação de um SMD.

\section{Palavras-chave}

Sistema de medição de desempenho; Avaliação de Desempenho; Indicadores. 


\section{Contents}

1 Introduction 12

2 Performance Measurement System 15

2.1 Designing a PMS 19

2.1.1 Performance metrics 20

2.1.2 Other components of a PMS 29

2.2 Transition from design to implementation 33

3 PMS Initiative in the Downstream Logistics Division 37

3.1 Methodological approach 37

a) Step 1: Evaluation of the context of work, data gathering and action planning 38

b) Step 2: The design phase and its deployment 38

c) Step 3: Evaluation 39

3.2 Overview of Petrobras Downstream Logistics 40

3.3 PM first steps and preliminary diagnostic 44

3.4 The design phase $\quad 46$

3.4.1 Performance metrics $\quad 47$

3.4.1.1 Costs metrics 51

3.4.1.2 Service Level metrics 52

3.4.1.3 Assets Management 54

3.4.1.4 Planning Deviation $\quad 55$

3.4.2 Other components of the PMS 59

3.4.3 Theoretical validations 66

3.5 The overall evaluation 69

3.6 Lessons learned 73

4 Conclusion $\quad 85$

5 References 88

6 Appendix 93 


\section{List of figures}

Figure 1-Sample of a Success Map 21

Figure 2 - Summary of the factors affecting a PMS 25

Figure 3 - Scheme of Downstream Logistics operations of

Petrobras 42

Figure 4 - Transpetro's official numbers from 2011

Figure 5 - Matrix for correlation between existing metrics and chosen clusters 49

Figure 6 - SMDO metric's - Clusters and Supply Flows 50

Figure 7 - Main SMDO screen - Menu of metric clusters 57

Figure 9 - Qualitative metric in SMDO Service Level cluster for Crude Oil

Figure 10 - Vessel's availability treemap $\quad 61$

Figure 11 - Example of elements' aggregation in a treemap 62

Figure 12 - Description of the Weekly and Monthly performance monitoring procedures

Figure 14 - SMDO screen of Assets Management cluster, Infrastructure Management division

Figure 15 - Example of Treemap - technological tool to better visualize deviations in a performance metric 


\section{List of tables}

Table 1 - Issues to consider when designing a PMS 22

Table 2 - Methodologies for clustering metrics 22

Table 3 - Drivers and barriers for PMS implementation 34

Table 4 - Nine steps to develop a PMS 37

Table 5 - The assessment of Downstream Logistics' PM from the as-is $\quad 45$

Table 6 - Description of the clusters 48

Table 7 - Real duration of research steps $\quad 70$

Table 8 - Lessons learned $\quad 74$ 


\section{1 \\ Introduction}

Competition between companies became a hard reality for successful businesses: resources, space, information are constantly disputed to face the challenge of serving clients needs more efficiently, and raise in market share. In order to proactively respond to these challenges, management requires up-to-date and accurate business performance information (Nudurupati et al., 2011). Within this context, performance measurement (PM) became an important element of operations management (Lohman; Fortuin; Wouters, 2004). It is also an accepted fact that businesses perform better if they are managed through formalized, balanced and integrated PM (Nudurupati; Arshad; Turner, 2007).

Organizations measure their performance in order to check their position (as a means to establish position, compare position or benchmarking, monitor progress), communicate their position (as a means to communicate performance internally and with the regulator), confirm priorities (as a means to manage performance, cost and control, focus investment and actions), and compel progress (as a means of motivation and rewards) (Neely, 1998).

There is a need to define and measure performance (Beamon, 1998) and to be able to drilldown to different metrics and different levels of detail in order to understand the causes of significant deviations of actual performance from planned performance (Lohman; Fortuin; Wouters, 2004). A Performance Measurement System (PMS) is a system (software, databases, and procedures) to execute PM in a consistent and complete way (Neely et al., 2002; Lohman; Fortuin; Wouters, 2004; Fernandez et al., 2012). According to Neely et al. (1996), PMS should provide data for monitoring past and planning future performance, and provide a balanced picture of the business, evidencing the relation between metrics and decisions taken.

The development of a PMS may conceptually be separated into phases of design, implementation, use and reviewing/updating (Bourne at al., 2000; Braz; Scavarda; Martins, 2011; Nudurupati et al., 2011). The design phase is about identifying key objectives and designing metrics. In the implementation phase, systems and procedures are put in place to collect and process the data that 
enables the measurements to be made regularly. In the use/review phase, managers review the measurement results to assess whether operations are efficient and effective, and the strategy is successfully implemented (Bourne et al., 2000). The review aims to constantly update the PMS (Kennerly; Neely, 2002; Lohman; Fortuin; Wouters, 2004). In accordance to Bourne et al. (2000), the PMS phases are conceptual because they can overlap as different individual metrics are implemented at different rates. Thus, some metrics can be implemented before all the metrics have been completely designed.

Among PMS phases, design is the one most privileged by scholars and practitioners, although all PMS phases have their importance. Bourne et al. (2000) highlight that it takes a considerable length of time to progress from design, through implementation to the metrics being used. Implementing a PMS can foster managerial changes and promote organisational learning by acquiring, storing, interpreting, and distributing data and knowledge about performance (Garengo; Nudurupati; Bititci, 2007). The transition between design and implementation phases requires a special attention, as it can compromise the entire effort already applied.

Empirical studies about initiatives related to PMS design are available in the academic literature, but there is still a need in the literature to develop more empirical studies related to the implementation phase (Bourne et al., 2000; Lohman; Fortuin; Wouters, 2004; Braz; Scavard; Martins, 2011; Nudurupati et al., 2011) and the transition between design and implementation phases. Regarding the PMS empirical studies, the oil and gas sector has been seldom studied. Within this context, the following research question has been considered: How should a PMS be designed and its implementation properly be prepared within an oil \& gas context? This dissertation goal is to analyze the evaluation of a practical PMS design case at the Downstream Logistics Division of Petrobras (Brazilian multinational company in the energy sector). The dissertation does not only focus on the system itself (technological parameters), but rather, it examines and highlights the knowledge obtained from designing and preparing the implementation of the PMS, supporting the description of a set of lessons learned through this initiative. The adoption of some practices during design phase in order to anticipate possible implementation problems was also evaluated, contributing to filling an identified gap in the literature. 
The present dissertation is structured in four main chapters, being the first one the introduction; the second the literature review related to PMS; the third chapter presents the case studied with a general context, the design phase of the PMS, the overall evaluation and the set of lessons learned; and the fourth chapter comprises the main conclusions of the research. 


\section{2 \\ Performance Measurement System}

PM is on the agenda of businessmen and scholars (Neely, 2002). Increasingly authors and commentators are discussing the multiple roles of measurement; it is now recognized that metrics allow managers to do far more than simply check progress; the behavioral consequences are frequently discussed; the value of benchmarking and external comparisons is widely understood; and the question of what data should be disclosed to external parties - especially shareholders - is actively debated, and by a diverse extend of followers (researchers) that can be considered at least by three different perspectives: accounting perspective, marketing perspective and operations management perspective (Neely, 2002). For this dissertation, the operations management perspective is the most suitable approach to be adopted.

There are many definitions for PM: a way of allocating and monitoring resources (Bowersox; Closs, 1996), a tool to determine whether the company's performance is in accordance with its strategic objectives (Beamon, 1999), the activity of measuring performance using performance metrics (Lohman; Fortuin; Wouters, 2004). However, due to its clarity and objectiveness, the definition of PM adopted in this dissertation and also in many other academic works (e.g. Lohman; Fortuin; Wouters, 2004; Parida; Kumar, 2006; Franco-Santos et al., 2007; Nudurupati; Arshad; Turner, 2007; Nudurupati et al., 2011; Braz; Scavarda; Martins, 2011) is the one presented by Neely at al. (1995): "the process of quantifying the efficiency and the effectiveness of an action". Efficiency is a measure of how economically the firm's resources are utilised when providing a given level of customer satisfaction, while effectiveness refers to the extent to which customer requirements are met. PM should be used to: (i) clarify strategy, (ii) communicate and drive strategy, (iii) check implementation of strategy and (iv) challenge strategy (Neely et al., 2002).

The evolution of PM is notably progressing from financial metrics to new manufacturing philosophies and dimensions (Neely, 2002; Nudurupati et al., 2011). Information systems for costing and PM had generally not been very helpful for managing operations, because such systems were based on overly 
simplified models of manufacturing activities and resource consumption, which produced inaccurate cost data. Moreover, in many companies there was a lack of non-financial metrics (Lohman; Fortuin; Wouters, 2004).

According to Neely et al. (1995, 1996), a PM which takes into account a set of performance metrics is called as a PMS, defined as a set of metrics used to quantify the efficiency and the effectiveness of actions. All PMS consist of a number of individual performance metrics and there are various ways in which these performance metrics can be categorized (Neely et al., 1995). Despite the research progress in the field, Franco-Santos et al. (2007) point out an existent lack of agreement in the literature on a definition for PMS, what leads to confusion and limit the potential for generalisability and comparability of research in this area. Their study analyzed 17 definitions of PMSs among specific scientific literature and each definition provides a different perspective on the concept. As a result of their study, the authors arrived into a set of key characteristics that a PMS must have, divided in features, roles and processes, as follows:

- features: elements or properties that make up the PMS - e.g. performance metrics, strategic goals and supporting infrastructure;

- roles: purposes or functions that are performed by the PMS - e.g. measure performance, strategy management, communication, influence behaviour and learning and improvement;

- processes: series of actions that combine together to constitute the PMS e.g. information provision, measure design and selection and data capture.

Therefore researchers need to be more specific and explicit about the characteristics of the PMS they investigate (Franco-Santos et al., 2007). In this dissertation, PMS is defined as proposed by Lohman, Fortuin, Wouters (2004): "a system to execute PM in a consistent and complete way (system understood as software, databases and procedures)".

According to Bititci, Turner, Begemann (2000), a dynamic PMS should be related to its capacity to change, to follow organisations' internal and external environment which are mutable, and it embraces: 
- An external monitoring system, which continuously monitors developments and changes in the external environment;

- An internal monitoring system, which continuously monitors developments and changes in the internal environment and raises warning and action signals when certain performance limits and thresholds are reached;

- A review system, which uses the information provided by internal and external monitors and the objectives and priorities set by higher level systems, to decide internal objectives and priorities;

- An internal deployment system to deploy the revised objectives and priorities to critical parts of the system.

The statement that performance metrics change according to the internal and external environment has also been affirmed by Braz, Scavarda, Martins (2011).

Neely et al. (2002) highlight four characteristics of a good PMS: (i) it contains a balanced mix of financial and non-financial metrics; (ii) it helps you predict what is about to happen to your business, as well as enable you to understand what has happened; (iii) it encourages people to do things you want them to do; (iv) it is an integral part of a systematic process for reviewing the metrics and ensuring they stimulate purposeful action. According to these authors, a PMS can be examined at three different levels: (a) the individual performance metrics; (b) the PMS as an entity; and (c) the relationship between the PMS and the environment within which it operates.

A relevant aspect to highlight is the direct effect a PMS has over communication processes. PMS designers and users must emphasize the importance of generating a system supported by two-way communications to encourage knowledge-sharing, generate trust, and avoid resistance (Franco-Santos et al., 2012).

According to Franco-Santos et al. (2007), if a company does not have a specific process for selecting the metrics it is going to use to assess its performance (even if those metrics are imposed by external stakeholders); if it does not have a process for capturing the data to calculate its selected performance metrics; and if it does not have a process to distribute the results of the PM 
exercise (even if it is with a simple MS Excel ${ }^{\circledR}$ spreadsheet); then, it could be argued that this company does not have a PMS.

More recently, the term Contemporary Performance Measurement (CPM) has been adopted (Cheng; Luckett; Mahama, 2007; Burgess; Ong; Shaw, 2007; Franco-Santos et al., 2012). According to these authors, a CPM system exists if financial and non-financial performance metrics are used to operationalize strategic objectives, in a balanced approach. The definition of CPM is based on a number of assumptions. Firstly, the definition assumes that the role of CPM systems is to evaluate performance for either informational or motivational purposes (regardless of the organizational level at which performance is evaluated). Secondly, it assumes that CPM systems comprise a supporting infrastructure, which can vary from being a simple method of data collection and analysis to a sophisticated information system facilitated by Enterprise Resource Planning (ERP) platforms or BI solutions. Finally, it assumes that CPM systems involve specific processes of information provision, measure design, and data capture, regardless of how these processes are conducted. PMS adopting diverse metrics are also considered CPM systems, provided that those key metrics are linked to the organization's business strategy (Franco-Santos; Lucianetti; Bourne, 2012). According to Burgess, Ong, Shaw, (2007), differently than the traditional PMS (financial-based) CPM systems are more dynamic, have a flexible format and have a clear purpose of promoting improvement (in opposition to the monitoring purpose).

Beyond the term CPM, there are other nomenclatures used in the literature referring to systems dedicated to measure and monitor company's or process' performance; those terms mainly combine the words Measurement and Performance. Although the components of a CPM seem to become a tendency in performance evaluation, there are still not many articles using the term CPM System and nor is it predictable that the term will be largely used as PMS currently is, therefore, for the purpose of this dissertation, the term PMS will be used to express the whole system for measuring the performance.

Next, the dissertation presents more details regarding PMS designing and the transition from design to implementation. 


\section{1 Designing a PMS}

The design stage identifies the customers and stakeholders' needs and considers business objectives and a framework for adequate performance metrics and their attributes (Bourne et al., 2000).

Neely et al. (2002) propose four elements to be considered in the design process:

1. Point of entry (or launch) - this is how the design and implementation of performance metrics is introduced to the business;

2. Participation - this is who should be involved in the workshops;

3. Procedures - these are the set of tools and techniques which the management team work through together as a group during the workshops;

4. Project management - this is the administration support, facilitation and co-ordination required to progress the project.

Those are relevant aspects to be considered in the beginning of design phase.

According to Neely et al. (1996), firms which employ formal processes for PMS design find it significantly easier than those that do not to decide what they should be measuring and how they are going to measure it, collect the appropriate data and eliminate conflict in their measurement system.

The literature presents different approaches for designing a PMS (e.g. Globerson, 1985; Wisner; Fawcett, 1991; Fernandez et al., 2012) and/or helpful tools used for this purpose (Neely; Bourne, 2000). The methodologies usually differ in the number of steps and/or in the way those steps are followed; nevertheless all of them demonstrate a special concern about connecting the system with strategic matters of the company, always regarding operational issues (such as information technology and processes). The main relevant aspects in the design phase are described next. 


\subsection{1 \\ Performance metrics}

According to Burgess, Ong, Shaw (2007), the choice of performance metrics is one of the most critical challenges facing organisations in all business sectors and there is an immense value in the act of deciding what to measure (Neely; Bourne, 2000). Define the metrics has been detached by many authors as an important stage during PMS design phase (e.g. Globerson, 1985; Wisner; Fawcett, 1991; Neely et al., 1995, 1996; Krakovics et al., 2008; Lohman; Fortuin; Wouters, 2004; Braz, Scavarda; Martins, 2011; Fernandez et al., 2012). According to Neely et al. (1995), managers find it relatively easy to decide what they should be measuring. Among the respondents of a survey, 69 per cent agreed or strongly agreed with the statement "we find it easy to decide which of the financial aspects of manufacturing we should be measuring", while 72 per cent agreed or strongly agreed with the statement "we find it easy to decide which of the non-financial aspects of manufacturing (quality, lead times, etc.) we should be measuring". However, when four senior managers were asked to identify what they thought should be measured in their firms they identified over 100 different metrics. The problem, then, was not identifying what could be measured, but reducing the list of possible metrics to a manageable set. It is impossible for a manager to make decisions on the basis of 100 unstructured metrics (Lohman; Fortuin; Wouters, 2004), a large number of performance metrics also increases the risk of information overload - it becomes difficult to know which performance metrics should be prioritized (Tangen, 2004).

In the manufacturing literature it is frequently argued that performance metrics should be derived from strategy; that is, they should be used to reinforce the importance of certain strategic variables (Globerson, 1985; Wisner; Fawcett, 1991; Neely et al., 1995, 1996; Bourne et al., 2000; Lohman; Fortuin; Wouters, 2004; Braz; Scavarda; Martins, 2011; Fernandez et al., 2012). Although this does not always appear to happen in reality, the link between performance metrics and strategy has also been extensively explored in the business strategy literature. The key theme here is consistency - consistency of both decision making and action because a strategy is only realized as decisions are made and courses of action are 
pursued. Indeed, it has been argued that a strategy can only be said to exist when one can identify a consistent pattern of decisions and actions within a firm (Neely et al., 1995).

Neely and Bourne (2000) propose an interesting tool to link strategy and performance metrics, the "Success Map". This map is a cause and effect diagram that explains the organisation's strategy and the manager's theory about how the business operates. The success map explicitly lays out the levers that managers can pull and the impact that pulling these levers will have on the business performance. According to the authors, once the success map is described, then it becomes possible to identify the right metrics of performance, because the appropriate metrics will be those related to the levers the management of the organisation deems are the most important to pull at this particular point in time. A success map for a typical manufacturing company might, for example, argue that it is necessary for the business to improve operating efficiency. The way the business is going to improve operating efficiency is by improving delivery on time. The way the business is going to improve delivery on time is by reducing lead times and improving stock control. Finally the way the organisation is going to reduce lead times and improve stock control is by getting ideas from employees about how to achieve these ends (see Figure 1).

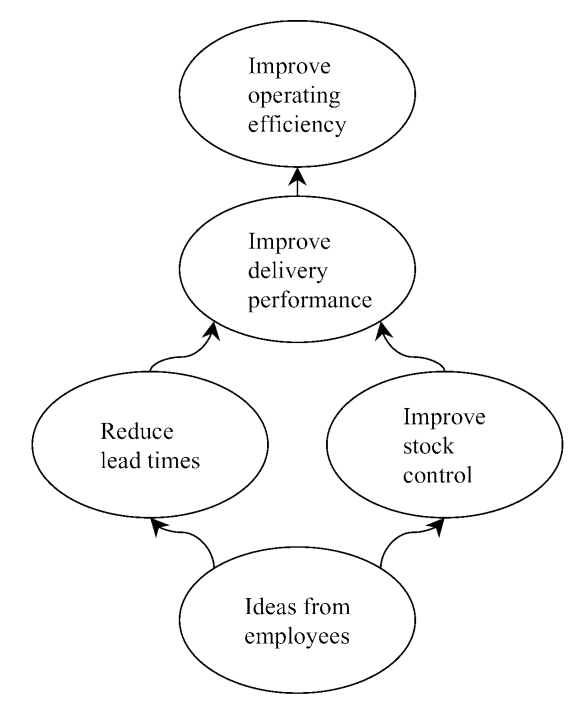

Figure 1 - Sample of a Success Map Source: Neely and Bourne (2000).

The Success Map has been adopted in many industrial cases, such as DHL and London Youth (Neely; Adams; Crowe, 2001). 
As a PMS is composed by a set of individual metrics, Neely et al. (1996) propose a list of issues that must be considered when choosing metrics to integrate a PMS:

Table 1 - Issues to consider when designing a PMS

\begin{tabular}{|c|l|}
\hline \multirow{4}{*}{$\begin{array}{l}\text { Individual } \\
\text { metrics }\end{array}$} & Metrics should be clearly defined/easy to understand \\
\cline { 2 - 2 } & Metrics should be purposeful \\
\cline { 2 - 2 } & Metrics should be practical. They should have the appropriate scale \\
\cline { 2 - 2 } & Metrics should form part of the control loop \\
\cline { 2 - 2 } & Metrics should be failsafe/self checking \\
\hline & Metrics should be cost effective \\
\hline
\end{tabular}

Source: Neely et al., (1996).

According to Braz, Scavarda and Martins (2011), several performance metrics can be observed in the literature but there is no consensus on the best way to classify them (one example of metrics' classification can be seen in Shepherd and Gunter (2006): qualitative and quantitative, cost and non-cost, and time, quality, flexibility and innovation). Since late 1970s, a number of frameworks, tools and techniques have been developed for designing PM, intending to answer the disquietude of deciding what to measure and how to structure a PMS (Nudurupati; Bititci, 2005; Nudurupati et al., 2011).

Table 2 presents a brief summary of two methodologies for clustering metrics in analytical frameworks. These methodologies are explained next.

Table 2 - Methodologies for clustering metrics

\begin{tabular}{|c|l|l|}
\hline \multicolumn{1}{|c|}{ Methodology } & \multicolumn{1}{|c|}{ Author(s) } & \multicolumn{1}{c|}{ Brief description } \\
\hline Balanced Scorecard (BSC) & Kaplan and Norton (1992) & $\begin{array}{l}\text { 4 perspectives to categorize the metrics: Financial, } \\
\text { Customers, Internal Process, and Learning and } \\
\text { Growth }\end{array}$ \\
\hline Performance Prism (PP) & Neely and Adams (2001) & $\begin{array}{l}\text { Five interrelated facets: Stakeholders satisfaction, } \\
\text { Strategy, Processes, Capabilities and Stakeholder } \\
\text { contribution }\end{array}$ \\
\hline
\end{tabular}

Source: author of this dissertation.

Kaplan and Norton (1992) propose 4 perspectives to categorize the metrics in the Balanced Scorecard Model (BSC). Those authors were followed by a number of others that adapted the BSC to other realities, for example, Lohman, Fortuin and Wouters (2004) added two more dimensions (Sustainability and People) and Parmenter (2010) included other two dimensions to the BSC, but at this time they were Employee satisfaction and Environment / Community. Neely, 
Adams and Crowe (2001) and Neely and Adams (2001) propose what they call the second generation of measurement frameworks (just after BSC), the Performance Prism (PP). PP is composed by five interrelated facets: (i) Stakeholders satisfaction (broader than the BSC because it includes employees, suppliers, alliance partners and others, beyond shareholders); (ii) Strategy; (iii) Processes (in the sense of the common generic business processes); (iv) Capabilities (a combination of people, practices, technology and infrastructure that together enable execution of the organisation's business processes); and (v) Stakeholder contribution (a symbiotic relationship between the organisation and the stakeholder, no matter the class of the stakeholder).

Much broader than a framework composed by performance metrics, the Supply-Chain Operations Reference Model (SCOR), developed by the Supply Chain Council (SCC), provides a unique framework that links business process, metrics, best practices and technology into a unified structure to support communication among supply chain partners and to improve the effectiveness of supply chain management and related supply chain improvement activities. SCOR was conceived to allow evaluations and comparisons among supply chains, their activities and performance. It configures supply chain processes in five: Plan, Source, Make, Deliver and Return; and its attributes (characteristics of the supply chain that permit it to be analyzed and evaluated against other supply chains with competing strategies) are focused on the customers (1, 2 and 3) and on the company (4 and 5):

1. Reliability - achievement of customer demand fulfillment on-time, complete, without damage etc.;

2. Responsiveness - the time it takes to react and fulfill customer demand;

3. Agility - the ability of supply chain to increase/decrease demand within a given planned period;

4. Cost - objective assessment of all components of supply chain cost;

5. Assets - the assessment of all resources used to fulfill customer demand.

According to Stewart (1997), some of SCOR' advantages are: the performance comparison among practicing companies, within or outside the industry segment; the use of benchmarking and best practice information to 
prioritize companies' activities and the possibility of each company to evaluate their own processes effectively. Therefore SCOR set of metrics have already been considered as an inspiration for some authors who intended to explore its benefits: Wang et al. (2004) used SCOR model level 1 performance metrics as the criteria for supplier selection; Hwang et al. (2008) after the implementation of SCOR Model in a Taiwanese company managed to identify significant performance metrics to improve the material flow and enhance supply chain forecasting and planning; Huang et al. (2004) propose the use of SCOR performance metrics in the solution of network optimization problem.

Performance metrics are described by a series of attributes (such as name, objective or purpose, target, frequency, etc.) which are responsible to define metrics` functions, the moment and the way of using each metric (Fernandez et al., 2012). Some authors emphasize the importance of detailing those characteristics, in order to let them clear and available to be consulted. Neely et al. (1997; 2002) and Nudurupati, Arshad and Turner (2007) suggest the use of a Record Sheet to record the definition of the performance measure, while Lohman, Fortuin and Wouters (2004) propose a "metrics dictionary" (in practice not very different from the previous proposition). Due to measurement difficulties of some metrics, they may be redefined in order to turn the measurement more feasible (Globerson, 1985).

Besides the former authors, Bowersox and Closs (1996) distinguish between result metrics and metrics for diagnostic, into four categories: Quality / Customer satisfaction, Time, Costs and Assets (for example: a result metric is "Order Fulfillment" and the diagnostic metric correspondent is "Deliver on time"); and Beamon (1999) proposes three types of performance metrics: resource metrics (generally cost), output metrics (generally customer responsiveness) and flexibility (how well the system reacts to uncertainty).

According to Lohman, Fortuin and Wouters (2004), the presence of existing metrics and parallel PM initiatives have a fundamental impact on the development of PMSs and therefore must be considered during the design phase, specially when metrics are been chosen. When there are already some performance metrics in the organization, developing a PMS should to a large extent be understood as a coordination effort to understand current metrics in detail, to identify shortcomings, and to include ongoing initiatives that affect PM (such as new 
information systems, parallel initiatives for developing PMSs, and global scorecard development).

Kennerley and Neely (2002) developed a model to provide an understanding of the factors, both internal and external to the organization, that facilitate or inhibit the introduction of new metrics, the modification of existing metrics and deletion of obsolete ones. Figure 2 demonstrates how these authors summarize the influencing factors found in literature: drivers - factors that cause change to be necessary; barriers - factors that must be overcome if change is to be effective.

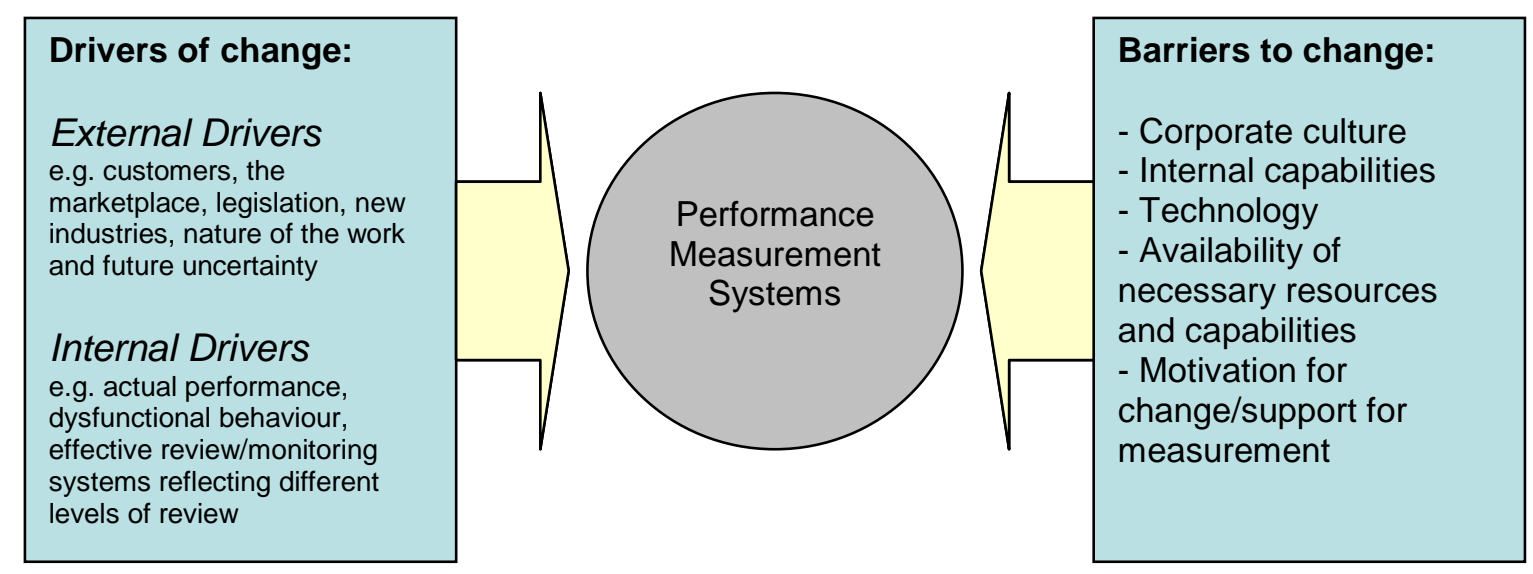

Figure 2 - Summary of the factors affecting a PMS

Source: adapted from Kennerley and Neely, (2002).

Approaches for designing PMSs use various ways to gather information, and there is much attention for an iterative process in which metrics are developed and adjusted as more information becomes available about strategy, customers, processes, and the availability of data. It is useless to design a PMS where data are difficult to obtain or are unavailable (Lohman; Fortuin; Wouters, 2004). Therefore, document the sources of information and check them out to confirm that the metrics will be calculated with the best data available is essential.

Besides the availability of data, according to Globerson (1985), there are five other major issues which have to be dealt with in establishing measurement procedures:

1) units of measurement - the purpose of the metric can be expressed by different variables with distinct unit of measure (volume, speed, weight, etc, and/or a relation between two variables); 
2) level of aggregation - performance can be measured either on an individual or a group level, the higher the aggregation level in the measurement, the lower the cost attached to the measurement, but there is a reduction in the reporting accuracy and in the ability of management to detect quickly the source of the operational problem and to respond accordingly;

3) measurement accuracy - the discrepancy between the reported value and the actual one, and the period of time elapsed from the time when the measured event took place to the time it was reported;

4) cross-check mechanisms - generating a conflict of reporting interest between divisions is a possible way to increase measurement reliability;

5) data collection and analysis media - two possibilities: data collection as part of the process and it does not depend on goodwill (automated), or data collection has to be initiated whenever needed and is not part of the process.

According to Bourne et al. (2000), the data collection, analysis and reporting should be automated as much as possible to save time and effort as well as to provide consistency.

Lohman, Fortuin and Wouters (2004) explicit two important decisions related to the act of measure: clustering the metrics and using a hierarchical structure within each cluster. According to the authors, clustering the metrics helps in creating a clearer connection between metrics and strategy, and improves communication about the metrics, because implement the process of constructing the hierarchy increases insight into the cohesion between metrics. Therefore, in the authors` case study, the PMS is represented by a three levels metric hierarchy model, where: the higher level is called cluster (6 in total), the intermediate level is defined as KPIs (Key Performance Indicators) and the lower level defined as PI (Performance Indicator), based on the data aggregation degree. That model was adopted by Krakovics et al. (2008), confirming one of its advantages: "for the high-level management team, the high-level of aggregation allows a quickly overview of the performance [...] once a problem is detected, it can be tracked down thanks to the hierarchy structure adopted". According to Globerson (1985), as far as it is possible to go deeper in a metric's parcel, the more it allows 
reporting accuracy and increases on the ability of management to detect quickly the source of the operational problem and to respond accordingly.

Once PM metrics were established, the design phase should assign their targets. A target is defined as the satisfactory level of performance and one must be established for every performance metric (Globerson, 1985). The presentation of a metric should be accompanied by an indication of the target to be achieved; specific numeric standards, or goals, should be established challenging but realistic, and once they have been reached a new target (more difficult) should be set (Fortuin, 1988; Crawford; Cox, 1990).

Globerson (1985) presents six possible techniques for assigning standards to performance metrics:

1) Work measurement techniques such as time study, predetermined time standards and work sampling - used for only one metric;

2) Analyzing of past organizational performance - past performance data for each metric may show not only deviations but also trends that can be depicted by a learning curve;

3) Management by objectives approach - based on different considerations such as needs and availability of resources;

4) Data comparison between organizations with similar characteristics such as type of business, technology or environment (benchmarking);

5) Economic considerations - profits may be obtained if expenses do not exceed a certain level, this level may be considered a standard;

6) Legal considerations - the law may state required performance levels for specific metrics.

Confirming the second item of Globerson's suggestion, many authors evoke the use of historical data to calculate the metrics, validate its results and assign targets (Lohman; Fortuin; Wouters, 2004; Krakovics et al., 2008; Braz; Scavarda; Martins, 2011), specially for new metrics. Nevertheless, according to FrancoSantos, Lucianetti and Bourne (2012), targets must have high strategic alignment, controllability, timeliness, and technical validity (especially when used for compensation purposes). 
According to Lohman, Fortuin and Wouters (2004), during the establishment of goals, feedback on the PMS is more useful if real data is used. In the case of dummy data, users are less motivated to explore the possibilities of the system and its shortcomings.

Similarly to Globerson`s forth suggestion, external benchmarks are also a considerable source of trustful targets (Fernandez et al., 2012). According to Neely et al. (1995), benchmarking is proving to be a topic of interest to both academics and consultants, and there are four basic types of it:

1) Internal - Internal to a corporation, but perhaps external to a plant or a particular business unit. One of the major advantages of internal benchmarking is that it minimizes problems of access and data confidentiality;

2) Competitive - This is probably the most beneficial form of benchmarking, but the collection of data which is directly comparable is very difficult;

3) Functional - This involves functional comparison with companies which are similar, but not direct competitors;

4) Generic - The study and comparison of truly generic business process, e.g. order entry, invoicing.

While most executives are not shy about setting stretch financial targets, the credibility of the targets is frequently questioned by those who must achieve them (Kaplan; Norton, 1996).

According to Neely et al. (1996), PMS design task goes beyond the selection and definition of an appropriate and practical set of metrics; it involves their integration both with one another and the wider environment, constituting the rest of the organisation and indeed the market place itself. For the authors, once it is decided what should be measured, it must be decided: how the metrics will be taken, the collection of the appropriate data and the elimination of conflicts in the measurement system.

During the design phase and under initial measuring stage, an important decision is the use (or not) of a prototype. The validation of metrics and procedures can be supported by the use of prototypes for visualising deviations in the results and tendencies that can be represented by a learning curve (Globerson, 
1985). Instead of focusing primarily on a thorough analysis of the information needed, an initial set of requirements can be specified and a prototype built to promote increases and changes in requirements while last the interaction with users. A prototype could give concrete examples of how the new PMS would look and this could stimulate discussion among the users and generate feedback to the designer. Next, by using the comments of the users, improvements would become possible, until eventually a satisfactory system is obtained. The prototyping would also be used to experiment with software designed for producing reports (Lohman; Fortuin; Wouters, 2004). The use of a prototype to allow metrics' maturity had been successfully adopted by Lohman, Fortuin and Wouters (2004), Braz, Scavarda and Martins (2011) and Fernandez et al. (2012), and mentioned by Globerson (1985), Krakovics et al. (2008) and Yigitbasioglu and Vulcu (2012) as an important and valuable tool to see if the concepts are feasible and if features can add value to the users.

\subsection{2 \\ Other components of a PMS}

As previously mentioned, a PMS is a system (software, databases and procedures) to execute PM in a consistent and complete way (Lohman; Fortuin; Wouters, 2004), and as so, the procedure to evaluate performance must integrate the system, and help answer the proper questions for that purpose.

For Globerson (1985), constant comparison between actual performance and standards is an essential part of every PMS, therefore a feedback loop to respond to discrepancies between standards and actual performance needs to take place in the PMS design phase (Braz; Scavarda; Martins, 2011). Causes for deviations lie either in the plan or in its execution. Hence, in order to eliminate undesired deviations, some action has to be taken and changes have to be introduced to the plan and/or the execution. According to Globerson (1985), corrective actions may be executed, either through an automated mechanism which is based on a set of procedures which define how to respond in different circumstances or through voluntary initiative (usually less structured than automated one). Nevertheless, 
some of the corrective actions may have undesired impact on coworkers and, as such, a manager may not feel comfortable to initiate them by himself.

In accordance to an automated mechanism to execute corrective actions, Platts (1994) argues that the requirements for well defined procedures, and simple tools and techniques are significant. Managers like to see the stages of the process explicitly stated. The requirement for a written record of the process is to ensure that data and assumptions can be revisited at future dates. This will be useful both at subsequent formal strategy reviews and, more importantly, as a strategic management tool which can be used to assess the likely impact of changes in the business environment, or incremental policy changes.

Lohman, Fortuin and Wouters (2004) describe two levels of control: the control function and the tactical or strategic one. At the operational level, a comparison of input and output values with predefined targets takes place. If there is a discrepancy between the actual value of the metric and the desired target, knowledge about the behavior of the organization is used to take an appropriate action (e.g. modifying the process). At the tactical or strategic level the control loop is used to evaluate and adapt control at the first level, by changing goals if necessary. With these two control loops, PM extracts the right process information and provides goal information needed to evaluate performance (comparison) as well as goals (evaluation).

Experiences prove the importance of someone responsible for the whole process, not just as a reporter, but as a manager in charge of concrete follow-ups and monitoring the effects of actions, as well as being responsible for improving the PMS itself (Lohman; Fortuin; Wouters, 2004). According to Neely et al. (2002), normally no one knows better a business than the one who is currently running it. What is needed is a process for extracting this knowledge and organizing it in a way which can be used to design and implement a PMS.

Management information systems (MIS) play a vital role in the upward flow of information. Haag, Cummings and Mccubbrey (2002) define MIS as a system that deals with the planning, development, management, and use of information technology tools to help people perform all tasks related to information processing and management. It corresponds to a supporting infrastructure that enables data to be acquired, collated, sorted, analyzed, interpreted and disseminated (Neely, 1998). 
MIS is designed to deliver many results and benefits (Nudurupati et al., 2011). However, in the context of PM, according to Neely and Bourne (2000), MIS is required to deliver one or more of the following:

1. Data collection, analysis and storage;

2. Improving operational control, speed and flexibility and hence improve efficiencies of business operations;

3. Improving communications, supporting the efficient and effective running of business processes.

One of the MIS tool is the dashboard, which can be regarded as a data decision supporting system that provides information in a particular format to the decision maker. According to Yigitbasioglu and Velcu (2012), dashboard is expected to collect, summarize, and present information from multiple sources so that the user can see at once how various metrics are performing. Performance dashboards might offer a remedy to the information overload problem by providing an all inclusive package for performance management, incorporating various concepts and applications such as strategy maps, scorecards, and BI (Business Intelligence) into one manageable solution. One of dashboard's purposes is to communicate in a visual way, and visualization is efficient if the maximum amount of data is perceived in a minimum amount of time. Dashboards often make use of colours to discriminate objects from one another or to recognize and identify them. Although the use of colours may improve the process of visualization, excessive use of colours can distract the user and may therefore have an adverse effect on decision making. Some of the newer generation dashboards include point and click interactivity that allow users to drill down information (dimensional analysis) so as to obtain further details on various performance metrics. Furthermore, dashboards can also help users to identify metrics that need immediate attention by visually alerting the user (through bright colours and/or flashing) when performance indicators go out of range (Yigitbasioglu; Velcu, 2012). An example of this kind of tool is the "treemap", that according to the former authors, is recommended when more complex and multidimensional data is used. The treemap is a visualizing graphic tool which allows drill down in parcels of the metric (called "elements"); combining two 
metrics' parameters (e.g. volume and price) in one easy display. The treemap was invented and first used for the management of the disk space of a server, and it allows users to explore and easily recognize complicated data relationships (Shneiderman, 1992). Corroborating the matter, Lohman, Fortuin and Wouters (2004) explicit the importance of flexibility while discussing the scorecard format and the report result of the performance monitoring process.

Although MIS is essential to support PM (Nudurupati et al., 2011), many PMS authors mainly describe the process of designing by mentioning metrics selection and the involvement of people in order to break resistance. Few references show in detail how the system works (display and metrics calculation rules) and what is the sequence of activities that should be followed in order to assess performance, as it can partially be seen in studies as Kaplan and Norton (1992) who illustrate metrics displays in the BSC cluster. Lohman, Fortuin and Wouters (2004) propose a dashboard with the higher level of metrics, gauges depicting the score numerically and graphically, historical data shown when demanded, easy access to lower metrics inside a cluster. Nudurupati and Bititci (2005) present a picture of their PMS' screens - the menu page and the summary report page. Nudurupati, Arshad and Turner, (2007) draw the to-be process map after PMS implementation. Krakovics et al. (2008) describe how metrics are calculated and their disposal in hierarchy. The few number of studies completely presenting the employ of MIS in a PMS initiative evidences a gap in the scientific literature.

In fact, many companies have failed to manage the most critical determinant of MIS, for instance, how people use it for PM and management. According to Nudurupati et al. (2011), change management plays a significant role in making the PM intervention successful. A PMS changes the way people interact with information before and after implementing the system and it is very important to well communicate the information (Nudurupati; Arshad; Turner, 2007). 


\section{2 \\ Transition from design to implementation}

As a formal deployment of the design phase, the implementation stage presents little solid research evidence in the literature (Nudurupati; Bititci, 2005), probably because implement a PMS in an organization is very critical (Parida; Kumar, 2006).

According to Neely et al. (2000), the process of designing a PMS is intellectually challenging, fulfilling and immensely valuable to those managers who participate fully in it. There is increasing anecdotal evidence, however, that the process of designing the PMS is not the most difficult task (Braz; Scavarda; Martins, 2011). The real challenges for managers come once they have developed their measurement system, because then they must implement the metrics. As soon as they seek to do so they encounter fear, politics and subversion (Neely et al., 2000).

Even in those cases where the organization manages to successfully identify the right set of metrics, the measurement initiative runs the risk of failure because of decisions that can be taken during the implementation phase which make the metrics effectively impractical in a particular organizational setting (Neely; Bourne, 2000).

As the implementation of a new PMS can be seen as "changing the rules of the game" or redistributing power in the organisation (Bourne et al., 2000), the transition between design and implementation is the moment in which a special attention must be dispensed. According to Neely and Bourne (2000), the mistakes made in the previous phase will directly impact the following one.

The resistance is a predictable movement of individuals and groups that may see the implementation as not being in their best interest, and so, actively or passively they resist to it (Bourne et al., 2000). Therefore, as soon as the main objectives of the PMS have been defined, and metrics, processes and technology have been established, implementation's practices should be introduced in order to show its advantages for the users. 
Bourne (2001) also mentions resistance as an important fact and concludes that there are two main drivers and four blockers as key forces to affect success or failure of PMS implementation, as shown in Table 3.

Table 3 - Drivers and barriers for PMS implementation

\begin{tabular}{|l|l|}
\hline \multicolumn{1}{|c|}{ DRIVERS } & \multicolumn{1}{|c|}{ BLOCKERS } \\
\hline 1) Top management commitment & 1) Time and effort required \\
2) The perceived benefits arising from designing, & 2) The difficulty of implementing the measures caused \\
implementing and using the performance & by inappropriate information being available from IT \\
measures & systems \\
& 3) Resistance to performance measurement \\
& 4) New parent company initiatives \\
\hline
\end{tabular}

Source: Bourne (2001).

According to Neely and Bourne (2000), too often individuals get frustrated that the process of building up and implementing a PMS lasts too long and can be ruined because of infrastructure' absence, and changes in organization's priorities.

According to Nudurupati and Bititci (2005), senior managers are responsible for changing the way they manage their business, their commitment should come in the form of a drive and they should be the first one to use the PMS. Managers should attend the workshops and become deeply involved in shaping the objectives and the measurement system. In accordance to the authors, in terms of people acceptance, some important enables in a PMS implementation are: (a) using the system for decision making, (b) acting as teams to solve the issues, (c) feeling confident about the information, (d) empowered to make decisions based on information.

Agreeing with the former authors, Nudurupati et al. (2011) add other reasons for difficulties in implementing PMS in many companies: high investments in data collection and the large number of metrics.

Bititci et al. (2006) studied five cases of PMS implementation and concluded that organisational culture and management styles have an impact on how PMSs are implemented and used, thus affecting their success or failure. As organisational culture elements, one can consider leadership and power, for example; and as management styles the authors selected four different ones to classify the organisations according to the way the work is performed. One of the conclusions of that study was the need for an authoritative management style during the implementation phase in order to be successful, nevertheless that style 
is not essential to sustain the continuing use of the system once an achievement culture is achieved.

According to Lohman, Fortuin and Wouters (2004), many companies seem to be facing serious difficulties in implementing PMSs that capture various dimensions of performance at various levels in a consistent way. The authors describe these difficulties as having various causes:

1. Decentralized, operational reporting history - too many reports and with inconsistencies;

2. Poor communication between reporters and users - the lack of interaction make the reports outdated in relation to the business as well as user preferences;

3. Dispersed IT (Information Technology) infrastructure - lack of data integrity between the reports, certain data can be extracted from multiple sources and this often leads to inconsistency, the infrastructure does not provide visibility over the supply chain;

4. Deficient insight in cohesion between metrics and uncertainty what to measure - since current reporting has an operational focus with parts of the chain, it is likely that certain high-level metrics are lacking.

PM implementations fail in many companies because of lack of IT support (Bourne et al., 2000), as it is one of the critical success factors for this kind of implementation (Nudurupati; Bititci, 2005). IT interventions impacting the normal course of PMS initiatives are not new in the scientific literature. Bourne et al. (2000) mention delays caused by IT in a case study about PMS implementations. Bititci, Turner and Begemann (2000), in a study for the development of a dynamic PMS, point out that IT infrastructure are currently limited and therefore it influences the design, links between systems and data management, impacting the final result of the PMS initiative. Finally Bourne et al. (2002) list seven themes that directly contribute for the success or failure of PM initiatives, and one is IT.

According to Bourne et al. (2000), some possible IT support during implementation could be provided by two forms: 
1. The business could build their own IT platform from the available resources using tools such as MS Excel ${ }^{\circ}$, MSS Access $®$, web development tools, etc.;

2. Buying an IT platform/ software available in the market, as ERP or Business Intelligence (BI).

Nudurupati, Arshad and Turner (2007) emphasize that in the PMS context, it is very important to communicate the information to the right people in the business in order to have the assistance for an efficient decision-making process.

Bourne et al. (2000), when describing the PMS phases, emphasize that the implementation phase may involve computer programming to trap data already being used in the system and present them in a more meaningful form. It may also involve initiating new procedures, so that information currently not recorded is captured.

Lack of MIS` support plays a major role directly or indirectly in influencing the failure of performance measurement implementation (Bourne et al., 2000; Nudurupati et al., 2011). An efficient result of a PMS can only be accomplished when managers and people involved have enough confidence in the information used and provided by the PMS. In relation to MIS, the authors affirm that there are lots of difficulties associated with gathering information from different sources. As a result, enterprises need to invest much of their time in data gathering.

Nudurupati et al. (2011) reinforce that MIS and change management play a significant role in making PM interventions successful. PMSs in organizations change the way people interact with information before and after implementing the system. For the authors, during the PMS lifecycle, change management and MIS play different roles for the success of the PMS and, in implementation phase, both aspects are significantly relevant for a good result. Advanced MIS is essential to create a favorable context for implementing and using PMS. As the academic literature underlines and case studies demonstrate, PM activities require MIS to support collection, processing and delivery of the data about performance (Garengo; Nudurupati; Bititci, 2007). 


\section{3}

\section{PMS Initiative in the Downstream Logistics Division}

The present chapter presents the case study carried out at Petrobras. The chapter offers the analysis of the PMS design and pre implementation in the Downstream Logistics Division of the company.

\section{1 Methodological approach}

There are many different methods that can be applied in operations management, for instance, case studies, surveys, modeling, simulation and action research. In terms of this dissertation, in the context of designing a PMS in the Downstream Logistics Division of a Brazilian energy company, the methodological basis which suited best was the case study as the complete research of the subject was done after many decisions had been taken and the project was already in an advanced stage.

The author of this dissertation adapted the nine step methodology from Wisner and Fawcett (1991) to design the PMS for Petrobras, steps that are displayed in Table 4.

Table 4 - Nine steps to develop a PMS

\begin{tabular}{|c|l|}
\hline Step & \multicolumn{1}{|c|}{ Action } \\
\hline 1 & Clearly define the firm's mission statement. \\
\hline 2 & $\begin{array}{l}\text { Identify the firm's'strategic objectives using the mission statement as a guide (profitability, } \\
\text { market share, quality, etc). }\end{array}$ \\
\hline 3 & $\begin{array}{l}\text { Develop na understanding of each functional area's role in achieving the various strategic } \\
\text { objectives. }\end{array}$ \\
\hline 4 & $\begin{array}{l}\text { For each functional area, develop global performace measures capable of defining the } \\
\text { firm's overall competitive position to top management. }\end{array}$ \\
\hline 5 & $\begin{array}{l}\text { Communicate strategic objectives and performance goals to lower levels in the } \\
\text { organization. Establish more specific performance criteria at each level }\end{array}$ \\
\hline 7 & $\begin{array}{l}\text { Assure consistency with strategic objectives among the performance criteria used at each } \\
\text { level. }\end{array}$ \\
\hline 8 & Assure the compatibility of performance measures used in all functional areas. \\
\hline 9 & $\begin{array}{l}\text { Periodically re-evaluate the appropriateness of the established PMS in view of current } \\
\text { competitive environment. }\end{array}$ \\
\hline
\end{tabular}

Source: Wisner and Fawcett (1991). 
The case study presented in this dissertation followed three main steps that are slightly similar to the ones proposed by Wisner and Fawcett (1991) as the practical approach was more generalist. The research steps are presented next with the reservation about their real duration, which will be explained forward.

a) Step 1: Evaluation of the context of work, data gathering and action planning

As each organisation has its own reality, culture, strategy and goal, in order to design and implement a useful PMS, it is vital to well comprehend the context of the business, its internal processes and people. This is usually the very first step of many PM researchers (Neely et al., 2000; Lohman; Fortuin; Wouters, 2004; Fernandez et al., 2012). The subject studied in this master dissertation was carried out by a team composed by two Petrobras direct employees (one of them is the author of this present study) and four external consultants full time dedicated to the project. Initially the team was expected to review all existing metrics in order to select and/or adequate the most significant ones. This first step was planned to last 6 months and comprised data gathering from existing processes, systems and metrics, like used metrics, names of responsible people, connections and interfaces among activities. Interviews and data collection from internal reports were important sources of information, as declared by Braz, Scavarda and Martins (2011).

After the first diagnostic of how performance was measured, it became clear what were the changes needed and a plan for the PMS design phase was established with: actions, responsible and term, all inside the context of a major project called SILA - Integrated System for Downstream Logistics Division (Sistema Integrado de Logística do Abastecimento).

This general evaluation is not directly mentioned by Wisner and Fawcett (1991), but it can be considered implicit as the authors describe the third step as developing an understanding of each functional area's role.

b) Step 2: The design phase and its deployment 
Design phase was planned to last 26 months and could counter with a special regimen of governance. SILA's governance had established a meeting with a Consultant Committee every two months to follow the progress of the project. This Committee was formed by 11 Downstream Logistics' managers whose respective teams would be directly affected by the changes proportioned by the project, as well as by changes in PM. The PMS design team usually utilized some of those meetings, and even extra ones, to validate every improvement done in the design phase. The project was in line with Neely et al. (2002) regarding the two important elements that, in their point of view must be considered in order to have a successful PMS design: point of entry and participation. The senior executive was directly sponsoring the initiative, what lead to a compulsory entrance, and since the beginning regular meetings with the design team and the Consultant Committee were established for validations. Managers' personal involvement was an important element to accelerate the decisions, especially during the design phase. Top management commitment is also mentioned by Bourne (2001) as a special driver to success in PMS design.

The design plan consisted of establishing metrics purposes, drawing the process of performance monitoring and defining requirements for the technological support tool. Beyond the definitions, initial tests were needed to assess consistency between theoretical concepts and practical results, as well as the efficiency of the MIS proposed, as, according to Lohman, Fortuin and Wouters (2004), it is important to spend a time in reflecting on differences caused by strategic actions that have been formulated to achieve the objectives. Interviews with managers, coordinators and analysts (18 people involved) throughout design and a workshop to align concepts with the managers were the main methodological tools adopted to support this phase.

This second step comprehends some of the steps proposed by Wisner and Fawcett (1991), more precisely steps 1, 2, 4 to 8.

\section{c) Step 3: Evaluation}

This phase was planned to last approximately 3 months and was constituted by surveys with participants and clients of the process and reflexions of the design 
team members about the progress of the initiative, lessons learned and feedback for key stakeholders.

It is similar to the last step proposed by Wisner and Fawcett (1991): "Periodically re-evaluate the appropriateness of the established PMS in view of the current competitive environment".

\section{2}

\section{Overview of Petrobras Downstream Logistics}

Downstream Logistics is the division responsible for all transportation and storage of crude oil and oil products through the supply chain: from platforms or refineries to the customers.

According to the International Energy Agency (2012), oil products are any oil-based products which can be obtained by distillation and are normally used outside the refining industry, such as liquefied petroleum gases (LPG), naphtha, fuel oil, gasoline, kerosene, etc. The Petrobras' operations divide those oil products in three categories: clear and dark (according to the refining portion), and special products (like asphalt, paraffins, sulfur, solvents, petroleum coke, etc). As clear oil products there are LPG, kerosene, jet fuel, gasoline, diesel and others, and as dark there are all kinds of fuel oil: heating oil, bunker fuel, etc.

All crude oil (nationally produced and imported ones) is mainly transported by vessels - few exceptions use pipelines for this kind of transport - filling terminal tanks and refineries, and using their storage capacity. Once the raw material is refined, the oil products have their transportation and storage also programmed by the Downstream Logistics team.

In order to clarify concepts, the oil industry is usually divided between Upstream and Downstream activities, but there is no unanimity in the frontier between them. Some authors define Upstream as the process that covers the exploration, production and transportation of crude oil and gas to the point of transformation into oil products (mainly refineries) and downstream activities deal with the processing of crude oil in refineries, the distribution and the marketing activities of all the oil products (Manzano, 2005). Others consider transportation 
and storage of crude oil as the beginning of Downstream activities, while preliminary investigations, drilling, exploration and production of oil are parts of Upstream activities (Rinaldi, 2008). There is also another definition, called Midstream (or Middle Stream) which is represented by the refining process ( $\mathrm{Li}$; Wang, 2008). For the purpose of this dissertation, Downstream activities will embrace the set of operations between platforms offloading and delivering to the customers. It includes all crude oil and oil products transportation, storage, refining and purchasing.

Figure 3 offers a general scheme of Downstream Logistics operations of Petrobras. The Crude Oil flow makes the main connection between production units and refineries. There are many different kinds of oils, regarding its intrinsic quality, and all refineries are projected to process a specific mix of oils. Therefore Brazilian oil cannot be totally refined by national refineries and there is a need for importation of lighter oils to supply local demand. As the storage capacity is limited and recently there is an overprice for heavy oils in international market (the hole majority of Brazilian crude oil is classified as heavy), Petrobras has became an oil exporter, and Downstream Logistics is the Division in charge of transporting the oil from platforms or terminals to the clients (oil companies abroad). The oil products supply's flow mainly connects Brazilian fuel production units (the refineries) to fuel distributors. For some special products the delivery is done directly to industries and other sort of companies, but it corresponds to a small volume compared to the big market of distributors. As the total demand for some products is higher than the Brazilian capacity of production (diesel, for example), Petrobras needs to import those products, which are normally sold in a FOB (free on board) modality of contract, and Downstream Logistics is the responsible to send the vessel for the operation of importation, as well as for exportation of products that are over produced in the country. 


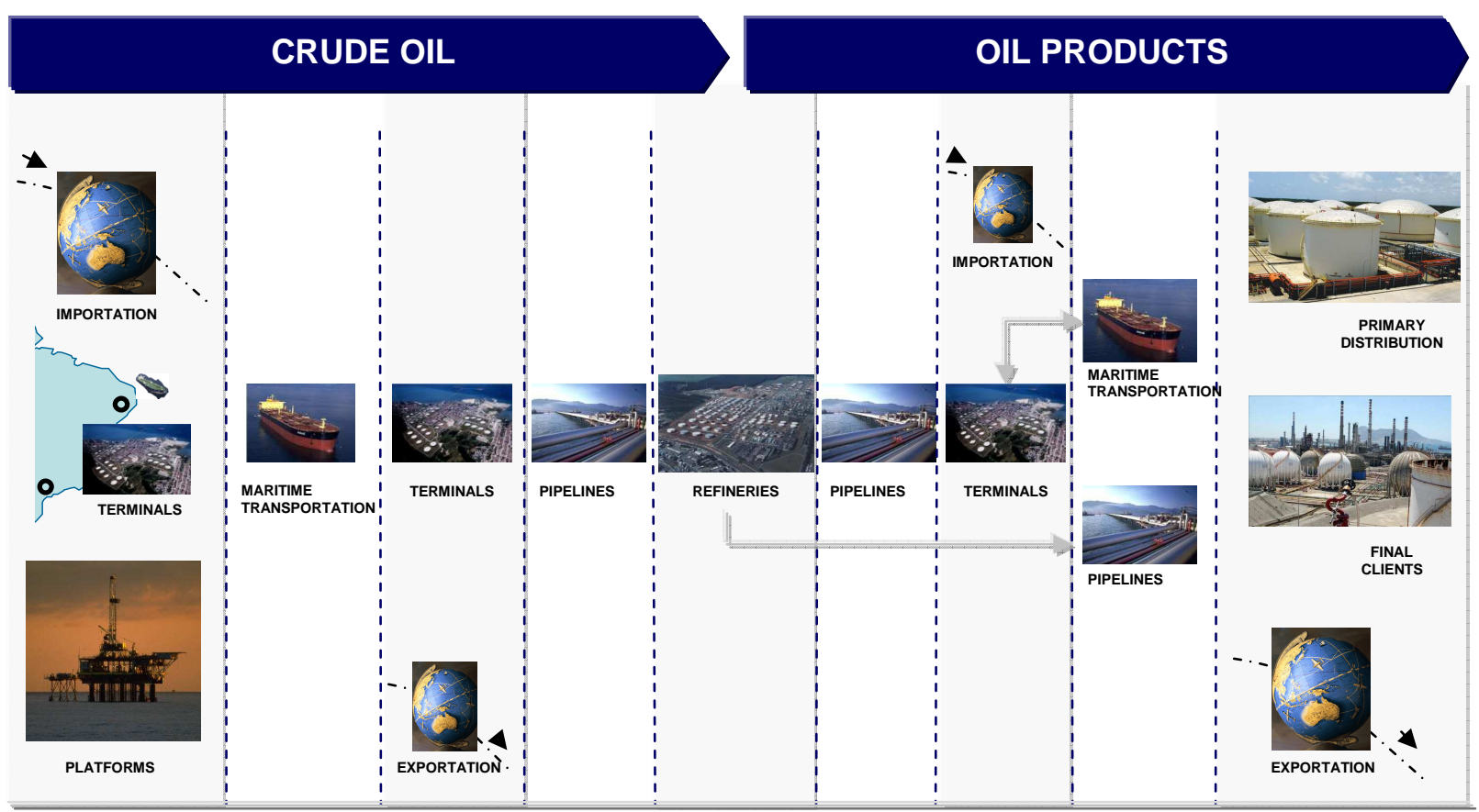

Figure 3 - Scheme of Downstream Logistics operations of Petrobras Source: author of this dissertation.

Downstream Logistics Division at Petrobras has its work force composed by approximately 460 people, divided in three big areas - Planning, Operations and Maritime Transportation - each one with their own group of managers and teams.

The Planning Department works for all logistics operations, regardless the products. Its main activities are: optimize the raw material and oil products' flow (maximizing the revenue), develop studies for improvement in the division, monitor the information flow through the different processes and evaluate Downstream Logistics performance. The Operations Department is mainly divided in operations with crude oil and operations with oil products. All kinds of products present particular aspects regarding transportation and storage, for example: volumes to be moved, temperature and quality specifications. Therefore there is a sector dedicated to programme the supply of only crude oil (national and international oil voyages and level of inventory in big oil tanks). There is also an analogue sector for oil products and another one for special products. A part from those three, some Downstream Logistics managers have their team divided in two: one part dedicated to manage crude and the other, oil products. That is the case of the Quality sector and another one responsible for hiring external services. The Maritime Transportation Department works for all products, but mainly with dedicated teams as the fleet is already specific according to the cargo: dark, clear, 
gas, etc. Managers in charge of vessels' operations and control, fleet planning and other activities need to be up to date with the operations of all kinds of products.

The Downstream Logistics plans and programs all logistics activities, and to execute the operations. It mostly works in partnership with Transpetro, one of Petrobras' subsidiaries firms. Transpetro is the biggest Latin American maritime enterprise and leader in fuel logistics transport. It owns oil products pipelines, terminals (marine and inland) and part of the vessels fleet used by Downstream Logistics. Figure 4 shows some figures of Transpetro.

\begin{tabular}{|l|c|}
\hline & \multicolumn{2}{c|}{ Cargo Moved in $\mathbf{2 0 1 1}$} \\
\hline Maritime Transport & 44 million tons \\
\hline Oil Pipelines & 395 million $\mathrm{m}^{3}$ of crude oil, oil products and alcohol/year \\
\hline Gas Pipelines & 51 million $\mathrm{m}^{3}$ of natural gas/day \\
\hline
\end{tabular}

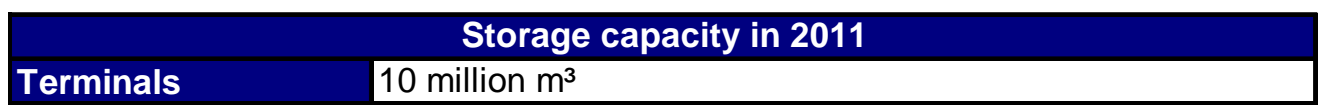

\begin{tabular}{|c|}
\hline Pipelines \& Terminals \\
\hline $7.179 \mathrm{~km}$ of oil pipelines \\
\hline 7.327 thousand km of gas pipelines \\
\hline Total pipelines operated: $14.506 \mathrm{~km}$ \\
\hline 20 inland terminals \\
\hline 28 marine terminals \\
\hline
\end{tabular}

\begin{tabular}{|c|}
\hline Maritime Transport \\
\hline Fleet with 58 ships \\
\hline 15 relief ships, to offload petroleum production offshore \\
\hline 8 ships to transport petroleum and dark products (fuel oil and bunker) \\
\hline 20 ships for clear products \\
\hline 7 ships for dark and clear products (diesel and gasoline) \\
\hline 6 gas ships to transport liquefied petroleum gas (LPG) \\
\hline 1 floating storage and offloading unit \\
\hline 1 maritime support vessel \\
\hline
\end{tabular}

Figure 4 - Transpetro's official numbers from 2011

Source: author of this dissertation.

For crude oil and the majority of oil products, Transpetro works in exclusivity with Petrobras (Downstream Logistics). Besides Transpetro, Downstream Logistics frequently contracts other companies for services, such as storage capacity in the northeast of Brazil, railway transportation in few routes from refinery to the coast and some vessels for foreign operations, as Transpetro's fleet is insufficient for the total volume transported.

The Downstream Logistics is in the border of major Divisions of Petrobras Exploration \& Production, Refineries and Marketing \& Sales, connecting them 
and turning viable the operations. Thereby it's a division whose performance must be closely monitored and any opportunity of improvement should be seized in order to achieve better results for the whole chain.

\section{3}

\section{PM first steps and preliminary diagnostic}

After the public announcement of Petrobras Business Plan 2008 - 2012 in August 2007, the expectation of big increases in oil production was confirmed. The announced rise in overall refining capacity also alerted Downstream Logistics that a change in everyday routine was eminent: transportation and inventory capacity needed to be adapted for the future.

Hence, under that context, after one year of the first ideas' maturity, in 2009 the main director of Downstream Logistics launched the project called SILA, which had as purpose the development and implementation of a management model for planning, programming and evaluating the supply chain of crude oil and oil products, integrating people, processes and technologies. The project was composed by five different lines of action: Process, Performance Metrics, Systems, Facilities and Change Management. Each of those axes had its own focus of work and the challenge was to integrate them all with the same purpose of promoting the evolution of Downstream Logistics. The focus of this dissertation regards to the Performance Metrics actions.

As part of the method applied, during six months (step 1 of the research method) the design team deployed a as-is diagnostic. The result of that diagnostic was: Downstream Logistics was partially and poorly measuring its performance. As described in Table 5, all elements found to prescribe that diagnostic have already been commented by some authors. 
Table 5 - The assessment of Downstream Logistics' PM from the as-is

\begin{tabular}{|c|c|c|}
\hline Category & Diagnostic & Literature References \\
\hline Metrics & $\begin{array}{l}\text { - Big number of metrics: some assess consequences, not the cause } \\
\text { for deviations; } \\
\text { - No connection or hierarchie among all existing metrics; } \\
\text { - Monitoring of specific itens from operation areas (e.g., number of } \\
\text { offloading operations, total volume sold of a specific product, average } \\
\text { volume transported by the vessels, etc.), without a general approach } \\
\text { of the overall performance; } \\
\text { - Mostly comparisons between Planning indications and real volumes. }\end{array}$ & $\begin{array}{l}\text { - Having a big number of metrics prevents quick decisions and } \\
\text { increases the risk of information overload (Lohman et al., 2004; } \\
\text { Tangen, 2004); } \\
\text { - The importance of consistency between strategy and } \\
\text { performance metrics, because a strategy is only realized as } \\
\text { decisions are made and courses of action are pursued (Neely et } \\
\text { al., 1995); } \\
\text { - There are metrics dedicated to evidence a specific result and } \\
\text { metrics used for performance diagnostic (Bowersox and Closs, } \\
\text { 1996); } \\
\text { - Metrics should provide data for monitoring past and planning } \\
\text { future performance (Neely et al., 1996). }\end{array}$ \\
\hline System & $\begin{array}{l}\text { - Long time spent in data collection; } \\
\text { - Many metrics were calculated and/or analysed in personal } \\
\text { spredsheets; } \\
\text { - One system available for all metrics, capable to calculate simple } \\
\text { operations, with limited storage capacity and each single metric } \\
\text { needed to be consulted at a time (no multiple vision). }\end{array}$ & $\begin{array}{l}\text { - Data collection and reporting should be automated as much as } \\
\text { possible to save time and effort as well as to provide } \\
\text { consistency (Bourne et al., 2000), } \\
\text { - A MIS proportions upward and horizontal flow of information } \\
\text { inside the organisation as well as outside (Nudurupati et al., } \\
2011 \text { ), } \\
\text { - A MIS can capture data, analyse and store it, improving } \\
\text { speed, flexibility and communication (Neely and Bourne, 2000). }\end{array}$ \\
\hline Process & $\begin{array}{l}\text { - Decentralization: all managers have their own performance } \\
\text { monitoring activity, with diferent responsible people working isolated; } \\
\text { - Lack of commitment from the managers: once a month, one team } \\
\text { responsible for evaluation presented the results of some comparisons } \\
\text { between Planning indications and real volumes (production of crude } \\
\text { oil and oil products, sales of internal and external market and some } \\
\text { refining numbers, such as intermediate products inventory), but } \\
\text { normally no manager attended to that meeting and nor all } \\
\text { programming and operations' teams were represented; } \\
\text { - Deviations in metrics' results did not have a formal consequence of } \\
\text { an improve planning. }\end{array}$ & $\begin{array}{l}\text { - PM should be formalized, balanced and integrated (Nudurupati } \\
\text { et al., 2007) } \\
\text { - Top management commitment and the perceived benefits } \\
\text { arising from designing, implementing and using the } \\
\text { performance metrics are important drivers for the success } \\
\text { (Bourne, 2001) } \\
\text { - The importance of corrective actions executed either through } \\
\text { an automated mechanism or through voluntary initiatives } \\
\text { (Globerson, 1985), with a well defined procedure (Platts, 1994) }\end{array}$ \\
\hline
\end{tabular}

Source: author of this dissertation.

Therefore, the as-is diagnostic presented to the Downstream Logistics' director and his managers was:

a) there isn't any vision of strategic goals for the whole division;

b) there is no connection between existing metrics;

c) there is not a well established procedure to investigate the causes for deviations;

d) there isn't a good software to help evaluating the performance.

All managers agreed that PM in the area had a big potential to be developed in order to achieve a more complete evaluation of how the operations were managed.

According to the definition chosen to explain PMS, "a system to execute $\mathrm{PM}$ in a consistent and complete way (system understood as software, databases and procedures)" (Lohman; Fortuin; Wouters, 2004), the Downstream Logistics didn't have a PMS at that time, only a set of isolated performance metrics disposed in a visualizing software. After the as-is analysis it became clear that 
there was a need for a PMS in the division, in order to fill the gap between the way PM was done and PM in a complete and efficient way.

As a conclusion from the first step of the case studied, the design team developed an action plan, which would last 29 months, divided as follows:

1. 12 months $=$ Design Phase part 1: definition of metrics, process and initial research for a technological solution;

2. 8 months $=$ Design Phase part 2: system development and final theoretical validations;

3. 6 months $=$ Practical validation of the PMS;

4. 3 months $=$ Evaluation of the system.

Items 1 to 3 correspond to the second step of the research method (Design phase and its deployment), while item 4 is the third and last step of the case studied. The evolution of the project milestones are described next.

\section{4 The design phase}

The design phase started after the approval by the managers, as affirmed by Nudurupati et al. (2011): "senior managers' commitment is essential for the involvement of all the teams". Some orientations were given by the board of managers involved and two premises of work were established: 1) existing metrics needed to be taken into account and 2) SCOR Model should be used as reference.

After research in the literature and in a base of practices owned by the consultants, the concept of PMS started to be considered by the design team. More than just a set of metrics, it was necessary to draw an efficient process to measure performance and to design a software tool to assist the process, as highlighted in Franco-Santos et al. (2007). Some indications of technology and metrics appeared, nevertheless the need of a main goal, or target for Downstream 
Logistics, was clearly one of the first things to be arranged. There was a lack of clear strategy for the Division.

The components of Downstream Logistic PMS are described next, as well as how choices and decisions were taken and communicated. In order to facilitate the description, the subject performance metrics is considered apart, although it was treated simultaneously with the process design and system (tool) selection during the design phase, as, in practice, one influences the other. In sequence, it is presented how theoretical validations were done.

\subsection{1 \\ Performance metrics}

To confirm Downstream Logistics' perspectives and purpose, during a meeting with seven managers, outside Committee, it emerged a definition for the Logistics' mission. That is to serve the clients, with the lowest cost, using efficiently the assets, as planned. After that consensus it became possible to verify the adherence between this purpose and the existing performance metrics.

Therefore, in accordance with Downstream Logistics mission, it was defined that there were four big classes of metrics to be considered: Costs, Service level, Assets management and Planning Deviation. These four classes of metrics became four clusters of metrics association, inspired by the clustering methodology used by Lohman, Fortuin and Wouters (2004), inspired in the BSC model.

There was a common effort to define the main objectives of measure for each cluster, and they were established as displayed in Table 6. 
Table 6 - Description of the clusters

\begin{tabular}{|c|l|l|l|}
\hline$\#$ & \multicolumn{1}{|c|}{ Name of cluster } & \multicolumn{1}{|c|}{ Purpose } & \multicolumn{1}{c|}{ Comments } \\
\hline $\mathbf{1}$ & Costs & $\begin{array}{l}\text { Quantify all costs involved in transportation, } \\
\text { storage and delivery to clients }\end{array}$ & $\begin{array}{l}\text { Crude Oil and Oil products operations have } \\
\text { different components of costs. }\end{array}$ \\
\hline $\mathbf{3}$ & Service Level & $\begin{array}{l}\text { Measure the fulfillment of all contracts or } \\
\text { agreements of services provided by Logistics }\end{array}$ & $\begin{array}{l}\text { The actors in charge (interfaces) vary } \\
\text { according to which product is being } \\
\text { considered (Crude Oil or Oil Products). } \\
\text { There are very few written agreements. }\end{array}$ \\
\hline 4 & Planning Deviation & $\begin{array}{l}\text { There are different kinds of resources } \\
\text { specially important for Downstream } \\
\text { Quagistics and each one has particular } \\
\text { metrics associated. }\end{array}$ \\
\hline planning orientations are been followed & $\begin{array}{l}\text { Measure resources' availability and } \\
\text { employment }\end{array}$ & $\begin{array}{l}\text { After Planning, Programming areas } \\
\text { italuate the master orientation and update } \\
\text { it in a more realistic plan. }\end{array}$ \\
\hline
\end{tabular}

Source: author of this dissertation.

Once the operational focus for the system was established, in order to emphasize it and turn the new PMS more familiar and simple to be called by Downstream Logistics' people, the design team chose one small name for the PMS: SMDO (the acronym for Sistema de Medição de Desempenho Operacional, in Portuguese, which means Operational Performance Measurement System).

A complete research about all existing metrics in Downstream Logistics was conducted. At the time, there were 245 metrics in total. Isolating the ones related with human resources management (for example, level of satisfaction with the benefits) and Opex (e.g. percentage of contribution for the total cost of Downstream Logistics), the first filter for relevant metrics came with 148 to be analyzed.

Withal, SILA Project selected part of the scope for investigations: crude oil and the main oil products, which include LPG (liquefied petroleum gas), Naphtha, Diesel, Jet fuel and Fuel Oil. Besides, in Downstream Logistics, among the 24 sectors, there was a clear division between sectors that were strongly related with the core business of Downstream Logistics and the ones with a role for support activities. Therefore, a more detailed analysis of the existing metrics was done only for the metrics related to the following processes: Planning, Programming, and Operating. As Planning it is comprised short and long term plans; Programming is related to the scheduling of operations and monitoring service level; Operating is the process related to day by day activities of following the deliveries, monitoring stock level and solving operational problems. This 
selection of processes led to a smaller set of 51 existing metrics to deep analyze and choose.

The link between Downstream Logistics' mission and PM is a pre requisite for an efficient PMS, as mentioned by Globerson (1985), Neely et al. (1995), Bourne et al. (2000) and others, and that statement was hardly pursuit by the PMS design team during the stage of selecting the metrics. Hence, it was constructed a matrix to help correlating the existing metrics with the four clusters chosen, as shown in Figure 5:

\begin{tabular}{|l|c|c|c|c|}
\cline { 2 - 5 } \multicolumn{1}{c|}{ Metrics } & \multicolumn{4}{c|}{ Correlation } \\
\hline 1. - - & Costs & Service Level & Assets management & Planning Deviation \\
\hline $2 .--$ & $\mathrm{H}$ & $\mathrm{L}$ & $\mathrm{H}$ & $\mathrm{L}$ \\
\hline $3 .--$ & $\mathrm{H}$ & $\mathrm{H}$ & $\mathrm{L}$ & $\mathrm{L}$ \\
\hline $4 .--$ & $\mathrm{L}$ & $\mathrm{L}$ & $\mathrm{L}$ & $\mathrm{H}$ \\
\hline$\ldots$ & $\mathrm{L}$ & $\mathrm{H}$ & $\mathrm{H}$ & $\mathrm{L}$ \\
\hline
\end{tabular}

Legend: $\quad$ H High correlation

Figure 5 - Matrix for correlation between existing metrics and chosen clusters Source: author of this dissertation.

The term "High correlation" means that the result of the metric is directly related to the purpose of the cluster (for example, high correlation with Costs means that the metric demonstrates part of a number that contributes to increase or decrease the cost to operate Downstream Logistics), and the term "Low correlation" refers to metrics that don't show any direct impact in the missions' execution. The use of a rank correlation with only extreme classifications (no medium stage) was a preferable choice for avoiding neutral position, and, as consequence, not contributing for a value added judgment. The classification provided by that matrix was the result of a qualitative judgment done by the team, according to what was described to be the concept of the existing metric (in a kind of "metric identity" - the same as mentioned by Lohman, Fortuin and Wouters, (2004), as "metrics dictionary"). In the end there were 15 metrics, among the existing ones, that were considered relevant and coherent with the purpose of the PMS.

Nevertheless, after a deeper analysis, it was concluded that the way those 15 metrics were calculated could not provide a mechanism to drilldown to different levels of detail, in order to understand the causes of significant deviations. 
According to Lohman, Fortuin and Wouters (2004), being able to drilldown in metrics parcels makes the difference to compare actual and planned performance. The disaggregation of the existing metrics and/or the revision of weighting criterion already adopted were facilitated by the tool component chosen for the technological solution which is explained in detail in the next section called "Other components of the PMS".

Besides the need for adaptations in existing metrics, the 15 selected were not enough to provide a complete diagnostic of Downstream Logistics performance. Thereby other metrics needed to be further developed and implemented. Each cluster was examined considering the SCOR Model, and it revealed opportunities to improve the set of metrics for SMDO. Measures as Perfect Order Fulfillment, Current Internal Capacity Utilization and a huge diversity of cost metrics became candidates to compose the System.

In general, it was observed that each supply flow coordinated by Downstream Logistics (crude oil and oil products) had a set of particular aspects related to the nature of operations required; crude oil has strict intrinsic quality parameters to observe when being exported, while oil products no. On the other hand, oil products deliveries in national market are surveyed by a target of service level agreed in commercial contracts, while national crude oil mostly supplies the refineries that belong to the company. Thus, the selection of metrics would be explicit in accordance to the supply flow, composing two different set of metrics for the four clusters of SMDO, as shown in Figure 6.

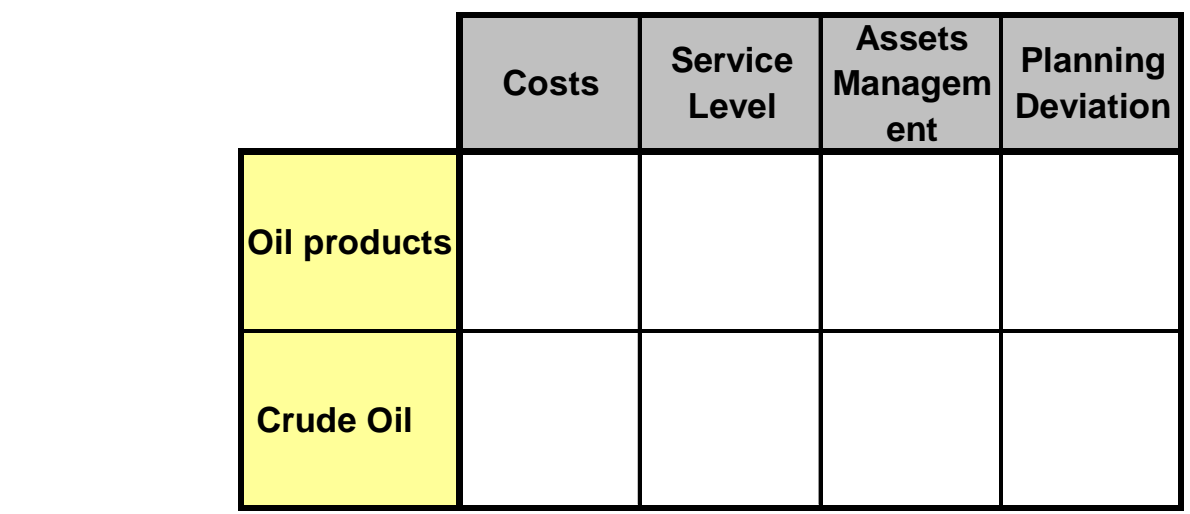

Figure 6 - SMDO metric's - Clusters and Supply Flows

Source: author of this dissertation. 
A detailed study and selection of metrics were developed for each cluster, considering existing measures already approved and SCOR metrics. A brief description of that selection phase is detailed next:

\subsubsection{1}

Costs metrics

As mentioned in Supply Chain Council (2008), cost is an important performance attribute and all costs related with operating the supply chain are worth to be measured. A particular characteristic of Downstream Logistics' business is the large number of vessels and the high cost for their hire and operations. Therefore, the cost of maritime transportation was already monitored by the company. Besides this cost, by that time other components were rarely observed (inventory cost and stock out cost), while others were never monitored (the cost of pipeline transportation, operations in maritime terminals and giveaway of oil products' quality - when a better product is delivered in place of an inferior one).

In order to cover all operations' aspects, the cluster Cost was designed with 12 metrics, divided as follows:

$\checkmark$ Seven metrics for Oil Products' flow:
a. Cost of maritime transportation;
b. Cost of pipeline transportation;
c. Cost of maritime terminal operation;
d. Cost of delivering abroad;
e. Cost of quality giveaway;
f. Inventory cost;
g. Stock out cost.

$\checkmark$ Five metrics for Crude Oils' flow:

a. Cost of maritime transportation;

b. Cost of pipeline transportation; 

c. Cost of maritime terminal operation;
d. Cost of delivering abroad;
e. Inventory cost.

\subsubsection{2 Service Level metrics}

The expression Service level is normally associated with a relationship between two entities: the supplier and the customer. At Petrobras Downstream Logistics that relationship can be by two forms: a) formally documented by a commercial contract, which establishes a minimum percentage of the total number of sales that must be entirely answered; or b) it can be empirical, following a common accomplishment of service. Apart from the exportation of crude oil and the delivery of oil products in the Brazilian market, the others Downstream Logistics service agreements are informal deals among Divisions, some of them already monitored by existing metrics (e.g. the rate of efficient offloading operations).

First of all, there was a need to define Downstream Logistics' clients for both supply flows. In terms of Crude Oil, the Downstream Logistics is in charge of offloading operations, refineries supply and external market operations (importation - the responsibility of sending vessels to charge at the date accorded with Commercial Division; and exportation - the responsibility of deliver the product on time and with agreed perfect volume at the client). On the other hand, for Oil Products, the Downstream Logistics needs to take away the excess of refineries' production and deliver it to the clients, as well as import and export Oil Products to supply national demand. As the Downstream Logistics works in partnership with the Commercial Division (for Oil Products, Downstream Logistics manages the inventory in all inland terminals while commercial analysts follow clients' contracts for pumping the volumes already sold), it became important to assess the service level of Downstream Logistics' deliveries at the storage bases in order to monitor if a final delivery problem was caused by the client, by bad management of the contract or by logistics' difficulties. The concept 
of order fulfillment described in the SCORE Model (Supply Chain Council, 2008) (delivery performance to customer commit date, delivery quantity accuracy and perfect condition - here adapted for quality perfect condition) served as inspiration for both supply flows, especially for exportation metrics because exportation requires a strong Downstream Logistics' engagement for quality assurance throughout the entire operation.

The cluster Service Level was designed with 19 metrics, divided as follows:

$\checkmark$ Nine metrics for Oil Products' flow:

a. Lost in refining production caused by logistics problems (oil products);

b. Time order for importation;

c. Perfect order fulfillment in exportation:

i. \% of orders delivered in full;

ii. \% of orders shipped on time;

d. Internal client's supply;

e. Service level in inland deliveries;

f. Service level in coastal deliveries;

g. Service level for filling up vessels.

$\checkmark$ Ten metrics for Crude Oils' flow:

a. Lost in Oil Production;

b. Service level in offloading operations;

c. Time order for importation;

d. Perfect order fulfillment in exportation:

i. \% of orders delivered in full;

ii. \% of orders shipped on time;

iii. \% of order shipped in perfect condition;

e. Lost in refining production caused by logistics problems (crude oil);

f. Service level in refineries crude oil' volume supply;

g. Service level in refineries crude oil' quality supply. 


\subsubsection{3}

\section{Assets Management}

This cluster has mainly been inspired by one of the performance attributes described by Supply Chain Council (2008) as the effectiveness of an organization in managing assets to support demand satisfaction. The assets assessment is also detached by Bowersox and Closs (1996) as an important category for PM.

The Downstream Logistics is in charge of vessels operations and management, inventory level control, pipeline programming, terminals and tanks supervision. Although the majority of these assets are formally under Transpetro's responsibility (terminals, tanks, some vessels), the Downstream Logistics is directly interested in their performance and so it does the monitoring of operational aspects strategically important.

The cluster Assets Management was divided in three parts, according to the nature of the asset, in order to facilitate its analysis of deviation, as listed next.

$\checkmark$ Four kinds of metrics for Fleet Management, divided in Coastal navigation and Ocean-going:
a. Vessels availability;
b. Tanks capacity utilization;
c. Time charter equivalent;
d. Deviation in the number of vessels planned.

The same metrics concepts apply for final products and crude oil supply flow.

$\checkmark$ Four metrics for Final Products Inventory Management:
a. \% of operational inventory over level;
b. Index of low stock;
c. Service level of certified inventory;
d. Inventory turnover. 
Crude oil inventory management metrics have not been approved during design phase because of delay in managerial alignment and in technological developments needed.

$\checkmark$ Three metrics for Infrastructure Management:
a. Pipeline capacity utilization;
b. Tanks capacity utilization;
c. Terminal capacity utilization.

These metrics joint final products and crude oil, as sometimes they compete for the asset.

\subsubsection{4 Planning Deviation}

The Downstream Logistics plays an important role of integration among all supply chain active players: the Division of Exploration and Production depends on the Downstream Logistics' offloading operations, the refineries are supplied and have their production delivered to farthest markets by the Downstream Logistics. At Petrobras, operational planning is realized with the participation of all departments involved in production, transportation, distribution and sales, centralized by a linear programming model which presents the best financial result for the company using data and premises provided by the managers. The Downstream Logistic' department of planning is in charge of managing the linear programming model and its indications for refineries' production, market supply in every sale's pole and purchases in foreign trade. Because of this particular characteristic, the planning orientations must be duly observed by the departments responsible for scheduling in weeks the consolidated planning number (e.g. crude oil monthly imported - cargos arrivals are organized in periods of ten days, sometimes week by week). According to Supply Chain Council (2008), planning is a process that aligns expected resources to meet expected demand requirements, balancing aggregated demand across a consistent planning horizon. For the design team, besides the importance of following planning orientation, monitoring 
deviations of planning instructions were already a practice before the revision of metrics and the design of a PMS start, therefore the cluster Planning deviation gained prominence and relevancy.

This cluster is divided in two parts: volume deviations and value deviations (monetary differences). Concerning volume deviations, four subdivisions were established: production, delivery, importation and exportation, as these four natures of operations are direct and indirectly under the Downstream Logistics supervision. Each subdivision has three stages of comparison, due to the process of planning and programming of volumes transportation: planned - the first planning number (from the linear programming model), programmed - a formal revision done by programming departments, realized - the volume produced or transported in the period. Crude oil and final products' flow have the same subdivision, lightly adapted, as described forward. Regarding value deviations, only comparisons between realized and planning financial results are relevant for analysis.

The metrics for the cluster Planning Deviation are described next.

$\checkmark$ Four metrics for Oil Products' flow related to volume deviations, subdivided in three: (1) realized versus planned, (2) programmed versus planned, (3) realized versus programmed:
a. Production accuracy;
b. Delivery accuracy;
c. Importation accuracy;
d. Exportation accuracy.

$\checkmark$ Four metrics for Crude Oil' flow, related to volume deviations, subdivided in three: (1) realized versus planned, (2) programmed versus planned, (3) realized versus programmed:
a. Production accuracy (unique comparison: realized versus planned);
b. Delivery accuracy (national refineries supply);
c. Importation accuracy;
d. Exportation accuracy.

$\checkmark$ Three metrics for Oil Products' flow related to value deviations: 

a. Delivery accuracy;
b. Importation accuracy;
c. Exportation accuracy.

$\checkmark$ Two metrics for Crude Oil' flow related to value deviations:
a. Importation accuracy;
b. Exportation accuracy.

SMDO Dashboard is presented is Figure 7, with the four clusters, two of them being subdivided.

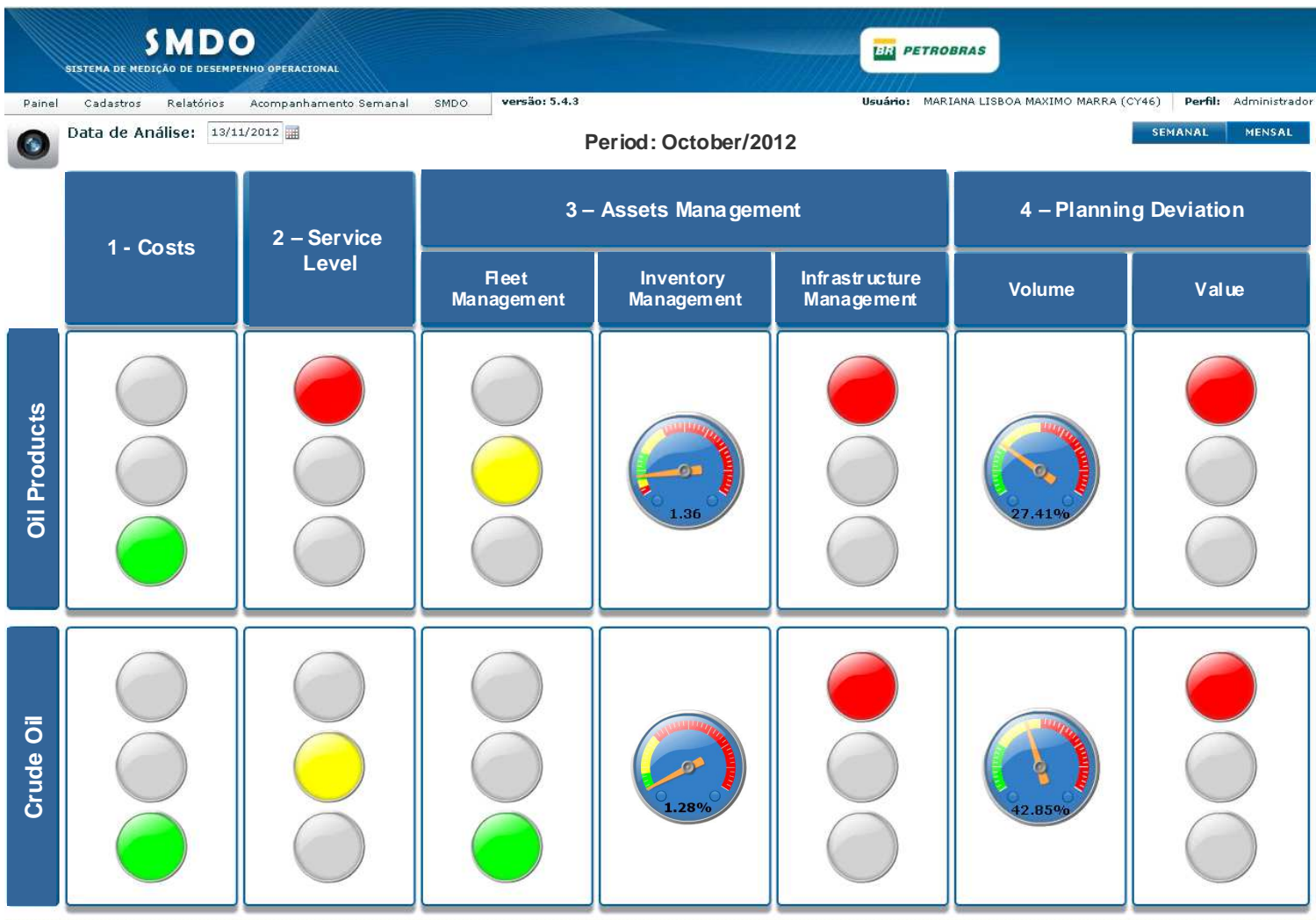

Figure 7 - Main SMDO screen - Menu of metric clusters Source: Petrobras SMDO system.

In total, SMDO contains 89 metrics, what makes their process of analysis quite complex, as previewed by Tangen (2004). In order to organize and simplify metrics analysis, Lohman, Fortuin and Wouters (2004) propose a hierarchy of metrics, as "it is impossible for a manager to make decisions on the basis of 100 unstructured metrics". The hierarchy inside each SMDO cluster has from two to three levels of metrics, as observed in Figure 8. 


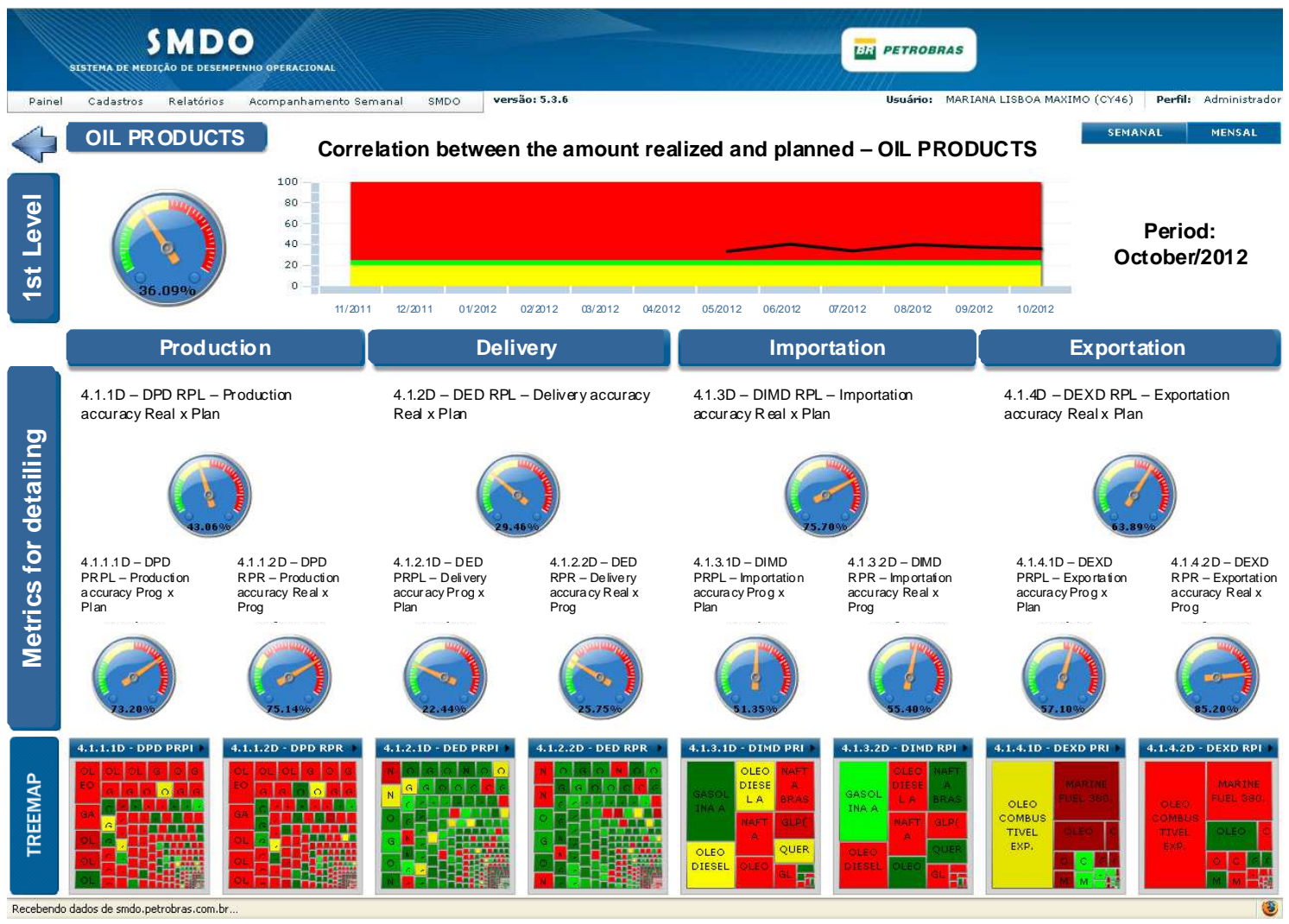

Figure 8 - Screen of Planning Deviation for Oil Products supply flow - three levels of metrics

Source: Petrobras SMDO system.

Differently from Lohman, Fortuin and Wouters (2004) proposition, in SMDO not all upper-level metrics correspond to a direct composition of lowerlevel ones. As an example, in figure 8, the upper-level metric considers only production and delivery parcels, importation and exportation accuracy are not taken in account for the final result, thus gauge must be interpreted as a deviation in production and delivery indications. In some cases it was not possible to engineer a linear dependency of the metrics and/or establish a prior common metric for the whole cluster. Thus, in accordance to a metrics' classification proposed by Shepherd and Gunter (2006) and Fernandez et al. (2012), some qualitative metrics were adopted in order to give a performance result for a set of distinguished metrics belonging to the same cluster, impossible to be aligned in one single concept. The example in Figure 9 illustrates the employ of qualitative metrics. 


\section{Service Level metrics - Crude Oil}

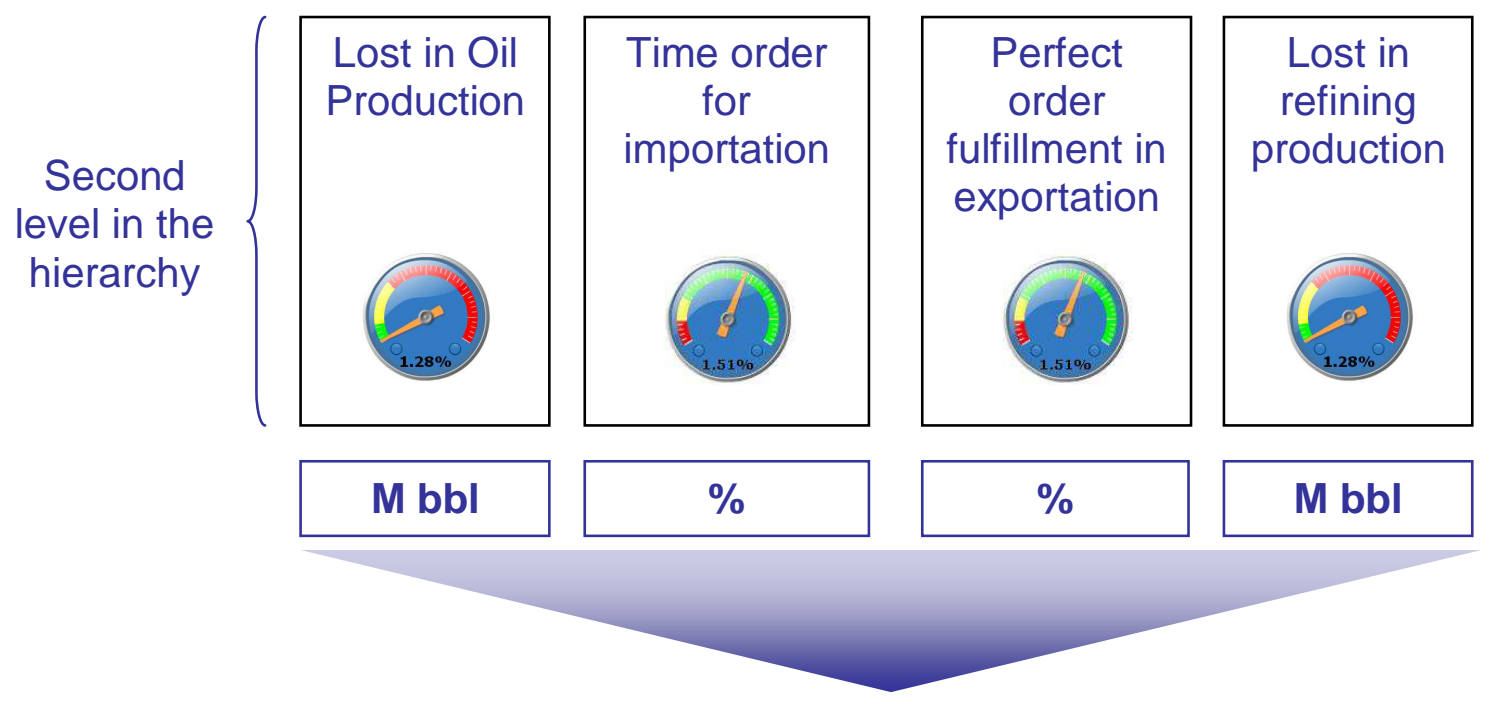

1st Level

Metric:

qualitative
General rule: If one of lower level metrics has a red result, the first level will light red; if none lower level metric is red and one is yellow, first level will light yellow; else upper level will light green.

Figure 9 - Qualitative metric in SMDO Service Level cluster for Crude Oil Source: author of this dissertation.

Qualitative metric has been employed in upper level of Costs, Service Level, Fleet Management, Infrastructure management and Value Planning Deviation clusters, for both the Crude Oil and the Oil Products' flows.

Additional SMDO screens are available in the Appendix I.

\section{4 .2}

\section{Other components of the PMS}

Metrics are one of PMS components, and in the study the revision of the available metrics at the time was the starting point for the design. After the first research for adherence among the present metrics and the identification of PM gaps, the design team started to search for IT solutions in PM.

The scorecard proposed by Lohman, Fortuin and Wouters (2004) became a good inspiration for SMDO because of all functionalities presented in the author's 
case study system: general dashboard, gauges, historical data, and easy access to lower metrics inside a cluster.

Moreover the resources previously presented, the adoption of the treemaps brought the agility needed for metrics' results analysis, as it combines two metrics' parameters (e.g. volume and price) in one easy display. For example, in a metric of vessels' availability, the result ( $80 \%)$ can be seen in parcels, as a certain number of vessels (60) are considered in the period of analysis. Every vessel is represented by a rectangle whose color represents the result of its performance in relation to the target (green is on the target; yellow is out of goal but inside a tolerance; red is totally out of goal - e.g. $100 \%$ is green, from 99 to $85 \%$ is yellow and under $84 \%$ is red) and the size of the rectangle represents the level of importance attributed to that vessel, in this case, the cost of its hire. It means, inside this treemap, expensive vessels appear in big rectangles, from top to bottom from left to right, as shown in Figure 10. The level of importance established among the elements was initially used as a weighting criterion in the final metric result shown in the gauge. 


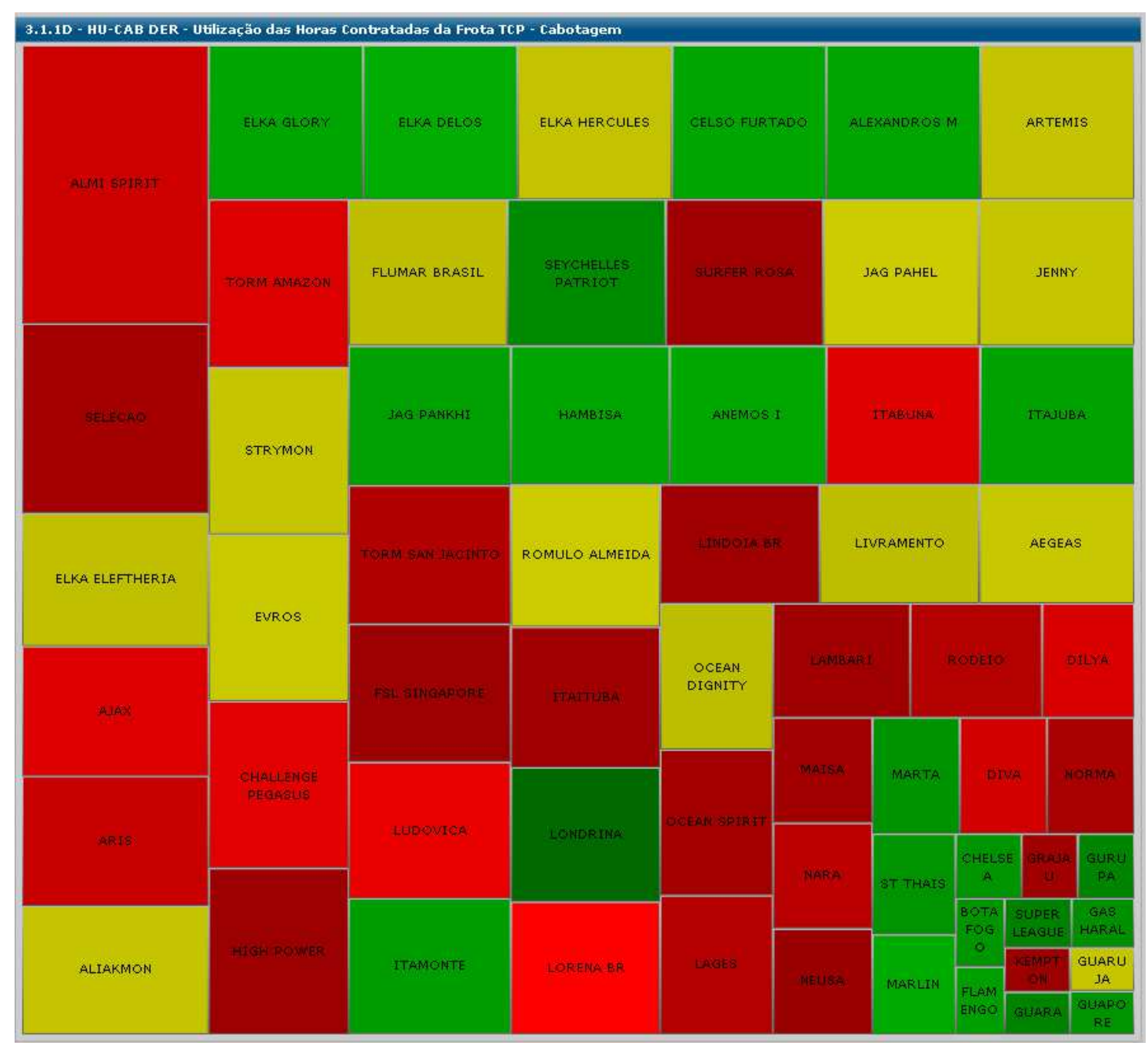

Figure 10 - Vessel's availability treemap

Source: Petrobras SMDO system.

A treemap also allows variations in the way the result is presented and that flexibility, called aggregation, became very useful for metrics' results analysis. Regarding the previous example given, it is possible to aggregate the vessels in classes (e.g. Aframax, Panamax, etc) and have a performance result for a particular class of vessel. An example of an aggregated result can be seen in Figure 11. 


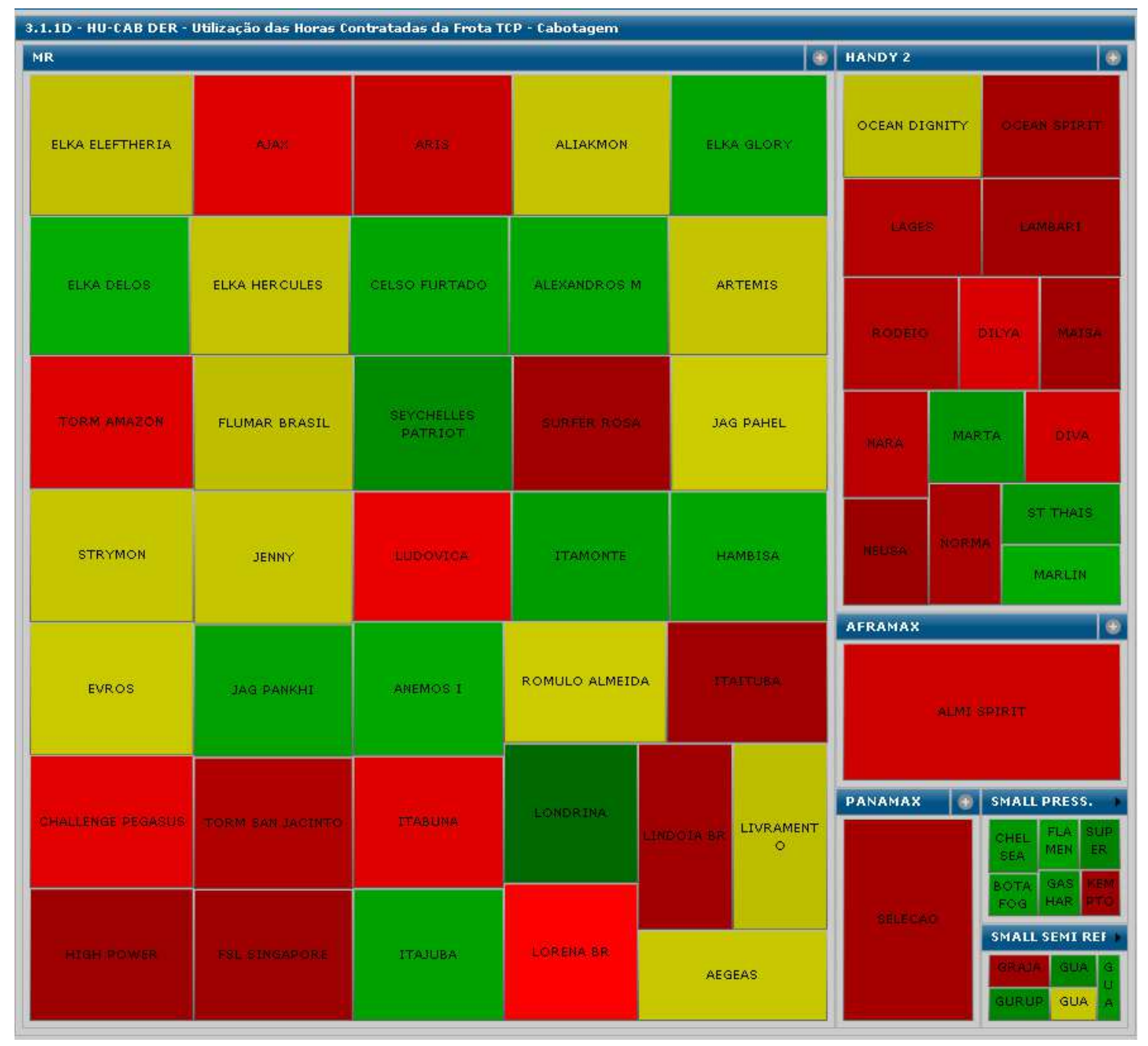

Figure 11 - Example of elements' aggregation in a treemap Source: Petrobras SMDO system.

Drill down in details inside a metric result was mentioned by Globerson (1985) and by Lohman, Fortuin and Wouters (2004) as an important characteristic of an efficient PMS, and in SMDO case the use of the treemap made the difference for deeper result analysis. In order to use a treemap, all metrics needed to be largely detailed as well as their databases and components. As a consequence, the metrics already in use in the Downstream Logistics needed to be modified because they were not calculated as a weighting average and normally parcels were not visible in the existing system. An example is the calculation of the metric Service rate in exportation: previously it was calculated only in a time perspective and by ship, the proposal was to calculate it by ship per client, 
ensuring the unity of each operation (a ship can travel more than once a month), so the final result of the metric was a little bit different. The 15 existing metrics selected to the SMDO needed to be carefully studied in order to provide a list of possible weighting criterion and aggregations. These metrics in particular were very questioned by the employees already used to their purpose and results, a movement of change resistance was observed.

Since the beginning of the study, the design team identified a gap of continuous improvement vision in the Downstream Logistics, based on a culture of limited responsibility (typical thought of doing only what is under your own department's responsibility, and this thought compromises a general and wide vision for the business). The following up of the as-is diagnostic needed to change the status of a passive performance gap identification for an active approach to solve the problem (if possible) or avoid future occurrences. There was a need for people involvement in the PM process and a clear description of the sequence of activities to follow in order to proportionate a valuable analysis. Regarding the SMDO and its metrics, the frequency of results' updating needed to be defined: all metrics could be calculated monthly, while just some related to planning deviation and inventory management could be updated weekly. Hence two procedures were designed: Weekly monitoring and Monthly monitoring, distinguished by the number of metrics involved and the direct result - a report is produced monthly and every week there is the proposal of only a presentation. Another procedure was designed with the purpose of promoting the continuous improvement vision, called the Corrective Planning Supervision. The description of the procedures follows next, in Figures 12 and 13. 


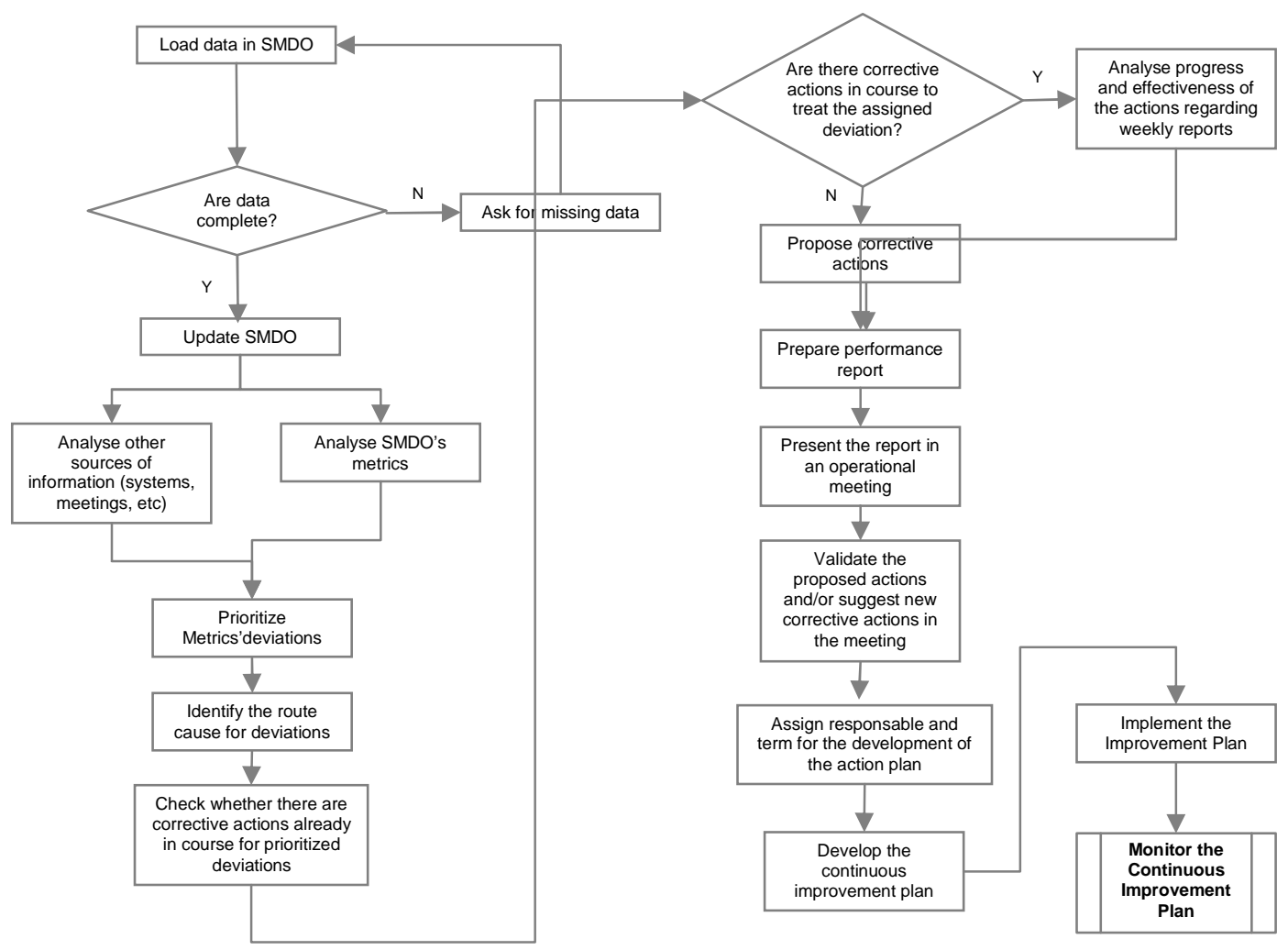

Figure 12 - Description of the Weekly and Monthly performance monitoring procedures Source: author of this dissertation. 


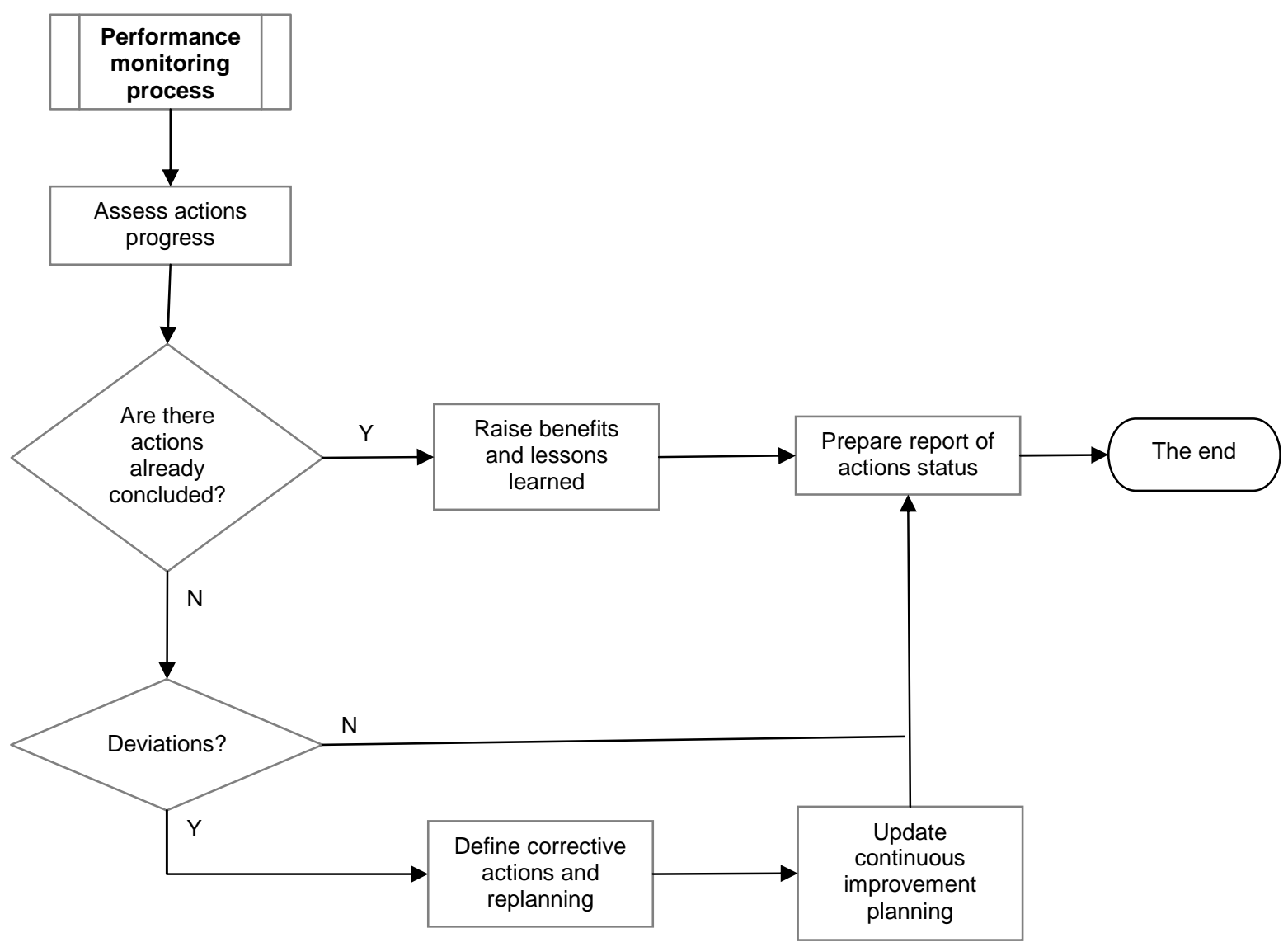

Figure 13 - Description of the Corrective Planning Supervision procedure Source: author of this dissertation.

The Performance Monitoring procedure (shown in Figure 12) can be categorized as the control function loop, as described by Lohman, Fortuin and Wouters (2004). It was designed to be executed by a team of six people, whose activities are divided following SMDO metrics' clusters (one responsible and one person as back for each cluster), and the system depends on external sources of data (systems or informal information coming from meetings). The Corrective Planning Supervision procedure (shown in Figure 13) focuses on proposing an action to correct relevant deviations and following it up.

One manager and his team were assigned as responsible of the PM process result, and, therefore, the main executers of the activities. This had been detached by Lohman, Fortuin and Wouters (2004) as an important lesson learned from a PMS successful design: the election of a PM Manager. The PM macro process was called Monitoring Process. 


\subsection{3 Theoretical validations}

In order to construct SMDO clusters of metrics, during the design phase some technical meetings took place with the purpose of validating concepts and aligning actual processes perceptions. Employees from the Planning, the Programming and the Operating departments from the Petrobras Downstream Logistics and a few internal consultants were asked to participate in formal discussions to confront ideal metrics with the existing ones, to verify data sources and debate about who would be the responsible for each information. By that moment, managers of SILA Committee had approved the main purpose of the clusters and the theoretical meaning of their metrics, but there was still the need of detailing the way the metric calculation would be done and the correspondence among the results, what means, the cause and effect relationship among metrics. During this validation process some new situations came up and are detailed next:

\section{1) Multiple data's source}

After first clarifications about existing metrics and the way activities in the Downstream Logistics were dependents one from another, the design team was able to map the systems that would serve as data sources for SMDO metrics (7 in total) and to start collecting some of that data in order to begin metrics calculations. Nevertheless, the technical meetings for validation served to understand that although company's official information was published with data coming from a specific system, day by day, for routine activities, people used to get data from other systems, usually the ones that provide information to the official system. When comparing the numbers, some inconsistencies were found, proving that Lohman, Fortuin and Wouters (2004) was right about the impact a dispersed IT infrastructure can have to provoke a lack of data integrity in an organization.

The Downstream Logistics' employees suggested the design team to collect data from the current operational systems instead of the formal one. For instance, in terms of inventory level data, the official system is the ERP, but the consulted team suggested taking it from a system in charge of controlling all movements 
from terminals and refineries. An specific report with data from ERP in the format needed would demand an extra effort by IT team, and this situation led the design team to reflect about the decision of adopting official sources of information or stand closer to real routine of activities and evaluate performance according to the way the employees were used to. The subject was submitted to SILA's Committee and the managers opted to have usual systems as formal sources of data for the metrics. The design team agreed with this resolution because the time and the effort needed to be dispensed for this task did not guarantee a consistency between data, and could even generate a third different number. This choice corroborates with Neely et al. (1996) because a good metric needs to be practical and cost effective, and with Nudurupati and Bititci (2005) because the users of the PMS need to be confident about the information generated by the system in order to use it.

2) Unavailability of data

During discussions, five of the proposed metrics (cost of pipeline transportation, cost of maritime terminal operation, cost of delivering abroad, service level for internal client's supply and time charter equivalent) were approved by the technical team consulted but with restriction: or data was not available or it was very difficult to be obtained. A decision needed to be taken: in some cases go ahead and specify reports with a special combination of data available from different systems, in others design a report to start collecting data needed, or give it up. Although according to Lohman, Fortuin and Wouters (2004), it is useless to design a PMS where data are difficult to obtain or are unavailable, the design team decided to evaluate the trade off between time and money spent and the benefits acquired from having those metrics in use. In order to keep the concept intended with these metrics, in that case the job was considered worthwhile and the Committee approved its development after other metrics resolutions.

\section{3) Lack of automated results}

After evaluation, it was concluded that four existing metrics previously approved to be incorporated in SMDO (Lost in refining production, Lost in oil production, Service level in offloading operations, $\%$ of crude oil orders in perfect 
condition) could not easily be automated as they depended on a qualitative analysis. It means every month an information analyst collects data from a system and manually calculates the metric's result, regarding a personal knowledge of the situation and some criteria already arranged with other departments. This condition deployed a discussion about how to incorporate these results in SMDO as IT development plans were to acquire all data from systems and calculate the metrics according to the functional specification provided. Automated data collection and data analysis were important evolutions previewed by SMDO design team, and mentioned by many authors as an advantage of an efficient PMS. Since a bigger decision was taken (as described next) this subject could have a reasonable solution in the case studied.

All these situations mentioned contributed to a major decision that changed the course of the project: the adoption of a prototype for testing the metrics (database and metrics calculation) and the Monitoring Process. Although the option for a prototype to allow metrics' maturity had been successfully adopted by many authors (e.g. Lohman; Fortuin; Wouters, 2004; Braz; Scavarda; Martins, 2011; Fernandez et al., 2012), at the beginning, it was partially accepted by the IT Division because, as initially wanted by the design team, IT had the pretention to develop all the informational solution for SMDO. Unfortunately due to difficulties in data collection and the need for flexibility that could not be offered by the first IT system's offer (total development), the proposal for a prototype gained more fans in both side (developers - IT, and users - design team) and it consisted of a provisional database development by the design team (in a Microsoft Access $®$ ) and a result visualization platform for the scorecard developed by IT Division.

Once it was decided, some important definitions (correct data source, specify parcels for metrics calculation and rules for filter in reports, etc) gained time to be taken calmly, after more tests. When the prototype was ready and tested, the Monitoring Process started to run internally its activities in order to elaborate the first monthly performance report. During six months, the metrics results were calculated in the in-house database, uploaded in SMDO and performance reports were presented to the manager in charge of the PM. For the performance analysts it was taken as an exercise for the new process, although at that time they were not counting with other departments' involvement in the 
elaboration of corrective actions planning. At the end of this experimental initiative, a workshop with all the Downstream Logistics' managers took place in order to compromise the participation of all departments in the month performance report, mainly with the proposal of efficient actions to solve problems or minimize the impact of unpredictable events, and officially launch the reports for the whole Division.

During the workshop the design team presented the SMDO set of metrics, its objectives and a suggestion of target for each one (based on a three month past data). An important decision expected from this event was the definition of which department would be responsible for the metrics results in partnership with the performance analysts, but it was not possible at that time. Probably because of the innovative way SMDO presents data and the weighting criterion adopted for metrics calculations, the managers presented resistance to some metrics, questioning the purpose and the validity of changing the way they were already used to calculate some of them. There was a general ambiance of denying criterion weigh in metrics' results, what managed to be partially converted at the end of the workshop. The official publication of the monthly performance report needed to be postponed because five managers asked for a private meeting with their teams and SMDO designers to review the objective and the parameters considered in some metrics. After that second validation, some metrics were remodeled and the IT Division needed to make adjusts in the scorecard. The dissemination in the Downstream Logistics of the Monitoring Process main product (the monthly performance report, using SMDO metrics results) started with a month delay.

\section{5}

\section{The overall evaluation}

As previously mentioned, the PMS design process at Petrobras Downstream Logistics was conducted by a formal design team full time dedicated and followed a structured plan divided into phases lasting 29 months.

During the plan's execution the design team faced various challenges that affected the final result of the PMS. At the beginning of the project, SILA's 
Committee deliberated that the initial schedule previewed could not be changed as that plan had been approved by the director and there was a contract with a consulting company for this initiative. Therefore there was pressure on showing a concrete result at the end of the period.

Even though many difficulties happened challenging the complianced plan, the unroll of the activities lead to believe that Neel et al. (1996) were right in affirming that companies which employ formal processes for PMS design find it significantly easier than those that do not to decide what they should be measuring and how they are going to measure it, collect the appropriate data and eliminate conflict in their measurement system. If the formal process had not been adopted, it would be certainly more difficult to develop the Downstream Logistics' PMS.

The under estimation of time led to an adaptation of the milestones for the deployment of the initiative: the milestones were overlapped one by another, and an inferior final result was obtained, as summarized in Table 7 and detailed next.

Table 7 - Real duration of research steps

\begin{tabular}{|c|c|}
\hline SMDO Design Plan & Real duration \\
\hline $\begin{array}{l}\text { Step } 1 \text { Evaluation of the context of work, data } \\
\text { gathering and action planning } \\
\text { (6 months - data gathering from existing processes, systems and } \\
\text { metrics; sources of information: interviews and data collection } \\
\text { from internal reports). }\end{array}$ & 6 months \\
\hline $\begin{array}{l}\text { Step } 2 \text { The design phase and its deployment } \\
\text { (divided in } 3 \text { parts) } \\
\text { (26 months - the design plan consisted of establishing } \\
\text { metrics purposes, drawing the process of performance } \\
\text { monitoring and defining requirements for the technological } \\
\text { support tool; methodological tools: interviews with } \\
\text { managers, coordinators and analysts, and a workshop). }\end{array}$ & $\begin{array}{l}\text { Part 1: definition of metrics, process and initial } \\
\text { research for technological solution (12 } \\
\text { months) } \\
\text { Real duration: } 20 \text { months, after } 8 \text { months IT } \\
\text { Division was involved and changed the final } \\
\text { result, system development started; } \\
\text { Part 2: system development and final } \\
\text { theoretical validations ( } 8 \text { months) } \\
\text { Real duration:10 months for the development } \\
\text { of the prototype (overlap); } \\
\text { Practical validations ( } 6 \text { months) } \\
\text { Real duration: } 4 \text { months for training }+6 \\
\text { months of process exercise; }\end{array}$ \\
\hline $\begin{array}{l}\text { Step } 3 \text { Evaluation } \\
\text { ( } 3 \text { months - surveys with participants and clients of the } \\
\text { process and reflexions of the design team members about } \\
\text { the progress of the initiative, lessons learned and feedback } \\
\text { for key stakeholders). }\end{array}$ & $\begin{array}{l}\text { Evaluation of the system ( } 3 \text { months) } \\
\text { Real duration: } ~ 1,5 \text { months, only by } \\
\text { Petrobras employees. }\end{array}$ \\
\hline
\end{tabular}

Source: author of this dissertation. 
a) Design Phase part 1: definition of metrics, process and initial research for a technological solution

Initially previewed to last 12 months, in terms of metrics' definitions it lasted approximately 20 months. The definition of the metrics and the process happened simultaneously, with time enough for process definitions and the beginning of technological solutions' research. After the first 8 months, the design team started meetings with the IT Division and two months latter all initial plan needed to be revised, as the IT and the design team opted to internally develop the metrics calculation database (design team responsibility) and sophisticate the visualizing tool of the new system (IT responsibility). That was when the decision of adoption a temporary prototype was taken. The possibility of changing plans because of IT limitation had been advised in some previous studies (e.g. Bourne et al., 2000; Bititci; Turner; Begemann, 2000) and was confirmed in SMDO case. The large number of metrics selected to be part of the SMDO also impacted the original project schedule, and contributed to the continuity of design phase part 1 during the second part.

b) Design Phase part 2: system development and final theoretical validations

The 8 months planned to be in sequence of the previous phase at the end were anticipated, due to the prototype's decision. It means design phase part 2 overlapped design phase part 1 . Finally 10 months were necessary for IT to develop the partial solution for the new system (only a platform for metrics' visualization), while it took almost 3 months for the design team to construct a database in Access ${ }^{\circledR}$ to be used as a temporarily database for tests. All activities from Design Phase part 2 occurred while metrics' definitions were still in progress (which were already consuming more time than previewed). Nevertheless, the new system development pressed metrics' resolutions (a complete list of all metrics' parameters and the election of each weighting criterion) because according to some data there was a need for adjustments in the technological tool. Even though the design phase part 2 helped accelerating some discussions, system development managed to last less than the previous phase, and thus the design team decided not to include some metrics initially in the SMDO, as they were still not mature in terms of data source, for example. During this time, theoretical 
validation was partially done and demands for changes and corrections in the system also contributed to the delay of this phase. The use of the prototype and the way database and visualizing system were conceived required an adaptation in the original design for the Performance Monitoring Process. The Performance Monitoring process would no longer count with data automatically generated, and thus, the data collection and the information upload activities needed to be added to the process.

\section{c) Practical validation of the PMS}

After the prototype's conclusion, the practical validations (tests) were done almost at the same time with some theoretical ones (data source and metrics calculation's rules). This phase was supposed to last 6 months and lasted 10 at the end, invading the following phase. The first 4 months were used for training the performance analysts in the new tool, to check data migration for SMDO visualizing platform, to explore the resources available and to verify if Downstream Logistics' employees consulted agreed with the way metrics' parcels were obtained and contributed to the final result. Some divergences appeared, mistakes were gradually treated and requests for changes were submitted to the managers' Committee. During six months the team of analysts responsible for PM started to test the execution of the entire process: from the data collection until the divulgation of the monthly performance report to a selected public (only two managers). Over that time, adaptations in the process became necessary to the achievement of the expected result and it contributed to lengthen the duration of that phase.

d) Evaluation of the system

This phase was supposed to happen during the project, with the participation of all members of the design team. However with the overall delay, the external consultants finished their contract when practical validation ended. The evaluation was conducted only by Petrobras employees, hard-pressured to officially launch the monthly performance report to all departments in the Downstream Logistics. Three months would already be a short time for a complete evaluation of the new system, but at the end it lasted a month and a half, with a small analysis result. 
Summarizing it all, the design team did not count with flexibility on time available to review and update the initiative's schedule. Anytime a new problem emerged, the sequence of activities was adapted to run during the months or weeks previewed, always compromising the following task. Therefore at the end the design team could not fulfill what had been mapped in the action plan derived from the as-is diagnostic. Instead of having a complete automated system, the designers (with the managers' approval) opted to develop a prototype of the system, allowing time for the maturity of metrics' concepts and the exercise of the new process routine.

\section{6}

\section{Lessons learned}

During SMDO design phase at the Petrobras Downstream Logistics many situations revealed to become challenges for the successful course of the initiative. Throughout SILA and PMS initiative, the design team collected a set of lessons learned and recommendations for future developments, which are listed in table 8 and detailed next. 
Table 8 - Lessons learned

\begin{tabular}{|c|c|}
\hline 1 & $\begin{array}{l}\text { PMS initiatives are long, the team involved must be motivated and a } \\
\text { flexibility on term should be considered } \\
\text { Long initiatives can be replaced by others more profitable in a short term } \\
\text { [Bourne et al., 2000]; it can deploy frustration [Neely and Bourne, 2000]; } \\
\text { detailed cost evaluation of flexibility in the project schedule can be } \\
\text { valuable. }\end{array}$ \\
\hline 2 & $\begin{array}{l}\text { Having a Committee of managers to deliberate in high level decisions } \\
\text { during design phase guarantees alignment between the PMS initiative and } \\
\text { the business } \\
\text { Top manager commitment proved to be very important: to commit the } \\
\text { teams and to assign experienced people to collaborate with the initiative } \\
\text { [Bourne et al., 2002; Bourne, 2001]. }\end{array}$ \\
\hline & As soon as the PM team is defined they must be involved in the initiative \\
\hline 3 & $\begin{array}{l}\text { The late involvement of performance analysts can generate resistance } \\
\text { [Bourne et al., 2000; Bourne, 2001; Neely et al., 2002] }\end{array}$ \\
\hline 4 & $\begin{array}{l}\text { The involvement of empowered people avoid rework } \\
\text { Organizational culture of "responsible and guilty" led to little commitment in } \\
\text { operational level, overloading managers [Kennerly and Neely, 2002; Bititci } \\
\text { et al., 2006]. }\end{array}$ \\
\hline 5 & $\begin{array}{l}\text { Maintain an updated documentation of the decisions taken provides more } \\
\text { agility in future stages } \\
\text { If a report with a tracking for all the most important decisions related to the } \\
\text { PMS is not prepared, the knowledge will be retained with the design team } \\
\text { and it will be always questioned. }\end{array}$ \\
\hline 6 & $\begin{array}{l}\text { A well conducted change management process makes the difference for } \\
\text { the PMS initiative's success } \\
\text { Current metrics addoption led to a crisis of responsibility for the results } \\
\text { [Bourne et al., 2000]; training and motivation of the performance analysts' } \\
\text { team; frequent communication about the progress of the initiative gained } \\
\text { appreciation. }\end{array}$ \\
\hline & $\begin{array}{l}\text { IT Division must be involved since the beginning in order to have a better } \\
\text { forecast of time and effort required for the initiative }\end{array}$ \\
\hline 7 & $\begin{array}{l}\text { Many systems provided data for the SMDO, multiple sources for the same } \\
\text { data (inconsistencies), the adoption of a new technological component for } \\
\text { the dashboard and the complexity of the business justified the importance } \\
\text { of IT involvement since the beginning, preventing some time spent and } \\
\text { bureaucracy [Bourne et al., 2000; Nudurupati and Bititci, 2005]. }\end{array}$ \\
\hline & $\begin{array}{l}\text { It is a waste of time to try to measure everything because having too many } \\
\text { metrics leads to a lack of priorities }\end{array}$ \\
\hline 8 & $\begin{array}{l}\text { The desire of measuring performance in a wide and integrated way } \\
\text { provoked a disquietude of selecting too many metrics and incorporate } \\
\text { current metrics desired by managers [Lohman et al., 2004; Tangen, 2004]. }\end{array}$ \\
\hline & $\begin{array}{l}\text { Process design and system development occurring simultaneously provide } \\
\text { more alignment in the final result }\end{array}$ \\
\hline 9 & $\begin{array}{l}\text { Strong correlation among metrics, systems and process; the process } \\
\text { designed need to be flexible in order to follow dynamic changes [Platts, } \\
\text { 1994]. }\end{array}$ \\
\hline 10 & $\begin{array}{l}\text { The value of a prototype and of a preliminary process exercise } \\
\text { Exercise and confirm all PMS elements: concepts validation, process } \\
\text { adequations, targets proposal; more credibility for the design team } \\
\text { because of new functionalities available. Adaptations and corrections of } \\
\text { possible future problems [Lohman et al., 2004; Braz et al., 2011; } \\
\text { Fernandez et al., 2012] }\end{array}$ \\
\hline
\end{tabular}

Source: author of this dissertation. 
1. PMS initiatives are long, the team involved must be motivated and a flexibility on term should be considered

In a company, an initiative which lasts more than two years can easily have its priority replaced more than once for other projects profitable in a short run. It happened during SMDO design that some managers postponed important meetings because of other projects and/or did not engage the best person of his team for technical discussions when demanded. It had been described before in the literature, Bourne et al. (2000) presented cases where managers found more pressing other priorities than the PMS initiative, as it was taking time to show a result.

Once a month, when there was a project status report meeting with the director, the managers from Committee asked to check the reporting progress in order to see if there was any pending, and when there was no progress to be reported, they got frustrated. The same feeling was sometimes experienced by the design team too as there were phases in which no concrete result could be obtained with less than a month, and the same difficulties were repeatedly reported. This reaction corroborates Neely and Bourne (2000) as the process of building up a PMS lasts too long and the main gains are obtained only in the end, more precisely after implementation.

By having clear the benefits of the initiative and with the real compromise of all managers it will be possible, in future occasions, to maintain the motivation of all people involved to acquire the final expected result despite the challenges and difficulties.

In SMDO case, for the workforce the final result was under expectations, mainly because at the end of design phase the system required manual data collection, not all metrics were developed nor were all relationships among metrics clear. However, the decision of concluding the design phase at the original term was taken by the managers at the Committee, without regarding the possibility of postponing the initiative in order to have a more complete final result. It illustrates a common trade off situation: cost and time - more time you spend in developing, more expensive becomes the solution, and the budget was 
already agreed with the director. It is hard to preview a different behavior in future occasions at Petrobras, but a conclusion taken is the importance of a constant monitoring of the project schedule progress, its milestones, and the value of a detailed cost evaluation of flexibility if justified changes of plan arrive during the initiative.

2. Having a Committee of managers to deliberate in high level decisions during design phase guarantees alignment between the PMS initiative and the business

Having a Committee of Managers personally delegated by the Director to validate the PMS main decisions during SILA's project, was a correct choice in terms of governance and a way to maintain managers' alignment with the importance SMDO would have for better results in the Division. Top manager commitment was proved to be very important, even essential, for the well development of a design PMS initiative, confirming Bourne et al. (2002) and Bourne (2001) comments about the importance of demonstrating managers' interest in this kind of project.

Besides that, the fact of being sponsored by the director attributed more prestige to the initiative: if during a presentation the director mentioned the SMDO, afterwards it was certain that some employees would start asking about its progress when meeting with someone from the design team. Actually, top managers' engagement was essential (a) to compromise the teams to contribute with the course of design phase and (b) to assign influencing and experienced people to collaborate with the design team, helping the promotion of good discussions with the group of managers and technical people directly involved with the current metrics or the performance monitoring process.

3. As soon as the PM team is defined they must be involved in the initiative

Although the activity of measuring performance in the Downstream Logistics was spread in the division, there was one department formally responsible to monitor the performance of some operational aspects. When the PMS design project was launched, the need for a more efficient and formal PM 
process appeared, and there was a first indication of this specific department to become the responsible for the new system. Nevertheless, it was only formalized when the process was already defined and the metrics were in the validation phase. Thus, it became possible to involve these employees and compromise them with the new system.

In the SMDO case there were only two direct employees full time dedicated in the design team. This situation coupled with the long duration of the initiative and the need for a practical result, led to an autonomous decision process by the design team, especially in the beginning. When the performance analysts started to be involved, the ones that would inherit SMDO, they felt as if everything was already decided and there was no flexibility to change. Even some technical employees from other departments that had been consulted latter on had the same feeling that it was too late to contribute. This situation and the resistance that emerged afterwards by the performance analysts is a common challenge barrier previously reported in some PMS design cases (e.g. Bourne et al, 2000; Bourne, 2001; Neely et al., 2002). It could have been avoided if the employees responsible for SMDO had been involved in its design since the beginning, as well as technical specialists.

4. The involvement of empowered people avoid rework

It happened more than once during SMDO design phase that technical meetings and interviews needed to be repeated because the person in charge did not consider himself able to answer for the whole department, although he had been nominated for that. Thus, whenever needed, it is imperative to ask managers to empower their substitutes and/or team members to answer and firmly decide as responsible for the subject. This aspect is closely related to the organizational culture, where the binomial "responsible and guilty" stimulates little commitment and is harmful in all hierarchical levels of decisions, from operational to strategic, overloading the upper level responsibility. Kennerley and Neely (2002) and Bititci et al. (2006) had advised that in terms of PMS, the corporate culture can become a barrier to change, and it was confirmed in the SMDO case. A lesson learned for future projects in relation to this subject: managers should be instructed to transmit to their teams the responsibility that everyone has in a specific level of 
competence and once delegated, anyone is capable to represent the entire department.

5. Maintain an updated documentation of the decisions taken provides more agility in future stages

Any time someone different is called to participate in an ongoing discussion, it is natural for the design team to rewind the context, ultimate decisions, impacts and consequences in order to proportion all information needed for the person to better contribute. Therefore it becomes very useful and time saving to document all phases in a structured way (for example, with decision, date, people directly participating in the meeting), because it happened in SMDO design that some issues needed to be recovered latter on, for instance, during the performance analysts' training. When the performance team was involved in the initiative (almost in the end of the validation phase) they were constantly questioning some data origin.

All SMDO metrics were properly documented in an identity form with its definition, parameters and metrics calculation rules, as well recommended by Neely et al. (1997; 2002), Nudurupati, Arshad and Turner, (2007) and Lohman, Fortuin and Wouters (2004). Nevertheless, the design team did not prepare a complete report with all decisions regarding metrics, process and system. Unfortunately, as it was not done on time, a report with a tracking for SMDO most important decisions should have been led as a legacy for performance analysts and all interested people. That is an important learning situation for future opportunities: a formal documentation must be prepared during the project.

6. A well conducted change management process makes the difference for the PMS initiative's success

People involvement was another challenging aspect during the SDMO design phase. Most of the study was directly taken by the design team, performance analysts and managers were mainly involved during advanced phases of validation, what made resistance of new metrics quite normal. Downstream Logistics' employees were already used to the previous metrics' system, with 
many prejudices against too many metrics and the need to justify any deviation. The idea of having two concurrent systems for the same purpose was not attractive, first because people thought they would be supposed to justify twice the same cause, and second because they thought they would lose the control as many proposed metrics were alike the existing ones. The crisis of responsibility for the results observed in the case had been described by Bourne et al. (2000) as a normal impact of PMS design and implementation.

Older employees were the most resistant with the SMDO initiative. This situation is understandable as they have seen many similar initiatives in recent years, some failed, some resulted in more work for them; therefore the design team managed to use in change's favor the fact that this time an specific team inside the Division would be in charge of the new system when the project had finished, and the main director was interested in the final result of the project. The process designed to compose the new system previewed the participation of people from different departments directly involved in the context of deviations, what was an innovative way to show value with a joint construction of corrective actions' plan.

Another important challenge was to train and motivate the team in charge of the new system to feed, calculate and generally analyze around 90 metrics every month. This group of people was used to periodically raise some numbers, analyze control items and justify metric's deviations based in punctual situations (no more than 10 metrics). There was a big expectation about the capacity of that team to generate accurate reports using SMDO. Hence the design team decided to develop a methodology to help the analysts to perform their tasks more efficiently (a sequence of aspects to consider and a program of meetings with the whole team to discuss the report).

Communication was identified as a key lever to minimize resistance and inside SILA's structure there was a special line of action dedicated to change management. The team promoted many informational campaigns during the project and whenever SMDO design team deemed appropriate, a special communication or general action (e.g. dynamic content to be presented by the Director to all workforce) was launched. Actions of frequent communication (mainly by email) were well evaluated by the Downstream Logistics' employees in more than one opinion survey's result. Another important initiative from 
Change Management team was the establishment of SILA's collaborator net, formed by one delegated person from each department to be the spokesman of his department. The collaborators helped in the advertisement of SILA's advances and they were responsible to communicate peoples' doubts about the new systems and processes. For SMDO, the collaborator net was initially useful as the collaborators were the official entrance door, and the design team solve time in some discussions and data collecting. Afterwards, for the majority of decisions, there was a need to validate aspects with more people from teams and, sometimes, directly with the manager. However, all those actions were not enough to cancel resistance, mainly from people that would be in charge of performance evaluation after the project and that were not involved in advance. All training material had the support of Change Management team to become more efficient in transmission of knowledge.

7. IT Division must be involved since the beginning in order to have a better forecast of time and effort required for the initiative

SMDO with its 89 metrics was designed to capture data from 7 different systems, each one with its own reporting formats and, what is the most challenging, admitting distinct aggregation of oil products (e.g. diesel aggregation in one system considers a light fuel oil for thermal industry, while in another system it is considered in the fuel oil aggregation). Business rules needed to be decided at the beginning of the initiative (Downstream Logistics' teams needed to agree with only one model of oil products) and IT Division needed to make the appropriate corrections. Besides that, there was the problem of multiple sources for the same information what generally leads to inconsistency. Checking out the better source and correct reports consumed a considerable time from IT teams and some dedication from design team as well.

All this situations were enough to justify the importance of IT involvement since the beginning of a PMS initiative. Furthermore, the development of a system with the dimension and complexity of the SMDO makes IT participation mandatory and admittedly valuable. In the Downstream Logistics' case, once the design team knew how SMDO would be (dashboard, functionalities and technological components - e.g. the treemaps), IT Division was convened. This 
association brought some practical implications: long time to understand the demand, bureaucracy in communication (all demands needed to be addressed to an intermediate department first), time spent to learn about the component tool required (the treemap) and slow capacity of responsiveness in case of changes. Besides that, after negotiations IT solution was a system with reduced flexibility, quite inappropriate for the living moment of design, a moment of concept tests.

What happened in SMDO case - the IT changed the scope and the duration of the initiative - corroborates with Bourne et al. (2000) and Nudurupati and Bititci (2005) that had described similar situations in which IT played a role compromising the success of the project. Probably it would have been different if someone from IT formed part in the design team since the beginning, checking and validating the proposals in terms of technology and information available at the company. Certainly with this competence inside the design team, the IT solution would have been more flexible to admit certain adaptations during system development, as metrics validations were still in course at the time.

8. It is a waste of time to try to measure everything because having too many metrics leads to a lack of priorities

In the Downstream Logistics, the desire for a wide and integrated PMS contributed to long discussions about what was important to be measured and how some relationships between metrics needed to be established inside a cluster (for metrics' hierarchy). The design team presented the result of a large analysis of existing metrics in relation to SCORE concepts and the clusters already chosen from Downstream Logistics' mission. However the evaluation of consistency between existing metrics and the proposed clusters was done by a qualitative judgment, according to what was described to be the existing metric, because of this there was not a clear and formal systematic of evaluation, what incurred, by the design team, in a fragile conviction of the set of metrics that should remain for the new system. Thus, during validation, some managers asked for the permanence of metrics already banished, as that is the case of three metrics from Service Level cluster (Lost in oil production, Lost in refining production caused by logistics problems - crude oil, and Lost in refining production caused by logistics problems - oil products) and one from Fleet Management cluster 
(Deviation in the number of vessels planned). The design team decided to agree with managers' suggestions for including these metrics, aiming to get their support for implementation and to break some possible resistance. Nevertheless, this managerial preference disturbed the hierarchical connection among metrics inside these clusters and resulted in more items to be considered, more job for data collecting and analyzing.

Although there are some analytical frameworks to cluster metrics and to help establishing a correspondence among them, there is no reference that mentions how to calculate a perfect metrics' number to effectively analyze company's performance, regarding its size, revenues, capacity and other criterions. But it is reasonable to think that 89 metrics is too much, even for a big division of a company as Petrobras. Although the design team have never previewed that all metrics' deviations needed to be explained in the monthly reports, for performance analysts' every metric deserves an attention and if someone makes questions about a red result, they must be prepared to explain it and show its correspondence in the cause and/or in the effect of other metrics, what is quite complicated in the case of 90 metrics. This practical situation corroborates with the comments made by Lohman, Fortuin and Wouters (2004) and Tangen (2004) about having too many metrics and their implications for analysis, as in the particular case of SMDO, the big number of metrics impacted to achieve an integrated vision of the business.

Neely and Bourne (2000) comment a relevant aspect that should be considered in future revisions or new metrics implementations: "Far too many organisations fail to understand the importance of the success map when developing their performance measurement systems and simply end up brainstorming what they should measure and then putting the resultant metrics into some form of performance measurement framework", and that was exactly what happened at the Downstream Logistics.

9. Process design and system development occurring simultaneously provide more alignment in the final result

In the original PMS design plan, the sequence of milestones in the project would be, first the selection of metrics, then the process definition and finally the 
technological proposition. Nevertheless the delay in the metrics' phase pushed the process design and pressed it to happen while some metrics' definitions were still on course and system development had already been anticipated. Although it was not previously planned and caused an impact in the final result, the simultaneity between phases resulted in a positive alignment among the SMDO components as some particular aspects of metrics' parameters impacted the new system (e.g. specific rules for aggregation according to the oil product), and the way the system was chosen to be developed, a set of activities needed to be incorporated to the process (e.g. manual data collection).

In practice it resulted in an opportunity to prove the strong correlation among metrics, system and process, in terms of PMS and to confirm that a well defined procedure with adequate set of tools and techniques allows an efficient PM development, as described by Platts (1994). The process design needs to be flexible in order to follow dynamic changes and reflect the real sequence of activities needed to acquire a good result, as it was done in the SMDO case.

For future systems development it is worth to coordinate efforts in order to revise the process at the same time as system's development is happening and thus guarantee the alignment between them.

10. The value of a prototype and of a preliminary process exercise

Initially the final result of SMDO design initiative would be a concrete system (technological solution) with the selected set of metrics and a process to evaluate performance. However, during the deployment of the project, the decision to use a prototype emerged, and it was just a possible solution to exit the conflict with the IT proposal in order to have a deliverable product at the end of the project. Meanwhile the systems' prototype resulted in an important way to validate concepts and adequate the process in order to have a definitive system afterwards, by exercising and confirming all PMS elements.

As described, almost half of SMDO metrics were new metrics for the Downstream Logistics' employees and there was a practical difficulty by the design team to define data source and eventually metrics calculation' purges when needed. In order to validate data, simulations were done in spreadsheets but the idea about whether the result of the metric was good or bad was not easily 
recognized. So the prototype helped the rapid visualization of the result, an easier correspondence of the metric with its cluster and a better comprehension about the role of the weighting criterion for the metric. For the definition of targets, as the prototype accumulates historical data, it became more practical to confirm preliminary suggested target values using a three month data series.

Another important aspect is that SMDO visualizing platform caused a very good impression among managers and their teams, and the design team gained more credibility because of the new functionalities available in the system, specially the treemap which allowed deeper details in metrics parcels, contributing to a more precise analysis of deviations. Managers wanted to see the metrics which were more related to their activities with good results. At first there was the challenge of breaking the culture of justifying all deviations, and once it was conquered performance analysts' started to counter with more contribution by other teams in finding the root cause for the main deviations.

Besides the difficulty of having a big number of metrics to analyze, in the beginning the performance team was not prepared to face the complex activity of a wide performance assessment using a huge system. Training the new process by running six month cycles of analysis helped the preparation of the team to develop a good report. Indeed the prototype and the preliminaries analysis helped a lot for corrections and adaptations in the process, in some metrics and in the system itself, certainly preventing problems that would appear in the implementation phase.

The experience with the use of the prototype during SMDO design initiative was very positive and recommendable for future developments, what corroborates Lohman, Fortuin and Wouters, (2004), Braz, Scavarda and Martins (2011) and Fernandez et al. (2012). 


\section{4 \\ Conclusion}

Although the literature presents empirical studies about initiatives related to PMS design, there is still a need in the literature to develop more empirical studies related to the implementation phase (Bourne et al., 2000; Lohman; Fortuin; Wouters, 2004; Braz; Scavarda; Martins, 2011; Nudurupati et al., 2011) and the transition between the two phases, design and implementation. Within this context, the goal of this dissertation was to present a set of lessons learned through a practical case of designing a PMS towards its implementation in a multinational company's division, considering the value of adopting some practices during design phase that could anticipate possible implementation problems highlighted in the literature (e.g. resistance, problems with data collection and identification of responsibility in the performance result).

The purpose of reporting and discussing a practical design experience in this dissertation is to bring empirical matter for PMS specialists in academy and industry, exemplifying important considerations and decisions. It is not the intention of this dissertation to make an exhaustive coverage of all the issues encountered in the design case investigated, but to highlight what seemed most relevant.

The implementation of a PMS requires a long phase of design, susceptible to many different challenges to its full success, and in terms of the SMDO initiative there was an extra component: the complexity related to designing a PMS for a company's division sized as Petrobras Downstream Logistics. Although some of the challenges arising from that phase were already known by Petrobras' team before the SMDO design project started (e.g. people's involvement and resistance, the existence of too many unstructured data sources, and a culture of justifications without a corrective plan), and thereby the team had previewed to deal with them during the initiative, in practice the development and implementation of the PMS has demonstrated to be very difficult, corroborating the reports of several authors on the subject.

SMDO final result was less than expected by the workforce because it had a temporary prototype with manual data collection and without the definition of all 
the metrics of the system. There were many factors that interfered in the project's progress with a direct impact in this final result, and most of them were related to failures in the project management, such as the lack of a dynamic evaluation of the milestones' advance, a constant revision of internal deadlines, a map with all stakeholders involved and the relevance of their participation in meetings for validation, or a good management of the scope defined and its revision according to the risks presented. Meanwhile the result obtained with SMDO certainly could had been better, it brought important cultural changes, especially in what concerns the focus of continuous improvement. The SMDO represented a huge progress for Petrobras Downstream Logistics Division to assess performance in a complete and efficient way: the proposition of metrics to evaluate performance along the supply chain, a system that shows the results in an easy visualizing platform which facilitates the identification of the main deviations, and a process to investigate the root cause of the problems and to propose corrective action plans. A real PMS brought a formal and structured way to report operational performance, causing admiration of other Petrobras' divisions.

The design of the SMDO helped Petrobras' design team and all employees more directly involved in the new system to learn a set of important lessons that will certainly be helpful in several other projects, even in a later revision phase of this system. The benefits obtained by the commitment of top managers, the selection of change management practices, the use of a prototype and the early involvement of IT Division as a partner in such complex initiative should not be neglected in future occasions, as they were key aspects for the development of the design phase and they certainly helped to prepare the implementation phase with its own challenges. The method applied constituted by the as-is diagnostic, followed by a current metrics' revision and definition of the ones that should be incorporated in the new system (based on several attributes), then the process design and the election of a technological tool to support it all was considered efficient and replicable for other PMS initiatives. Particular considerations are advised in order to have a more successful result: the openness to certain flexibility in project's deadlines if a cost evaluation justifies these changes, and the possibility of integrating the phases proposed in the methodology by running them simultaneously if the team is able to support it. In the SMDO case the 
overlap of the phases previewed resulted positive for the general alignment of the system.

Nowadays the Petrobras Downstream Logistics division is working on the implementation of the SMDO, what means the revision of all specifications for the definitive system solution (unique and automated) with the whole set of metrics incorporated to the scorecard. This present phase comes up with challenges but they are more easily accepted by the employees because the process and part of the technological solution are no longer new for them and they already perceive more tangible benefits coming from the system.

The study presented in this master dissertation contributes to fill an identified gap in the literature, the lack of empirical and longitudinal studies that report experiences, methods and difficulties associated to the transition between design and implementation phase of a PMS. The underlying study provides evidence of a logistics' division of a single firm with a specific product group, which limits the extent to which the findings can be generalized across a wider range of divisions, product groups and industries. As comparable studies in the literature are still amiss this investigation cannot claim to be anything more than an initial step towards the study of a topic that is likely to grow in importance as firms continue to expand their efforts in the development of PMS in their operations. Future studies might want to test and expand on the dissertation's findings, which go beyond the design phase, detailing the concrete results and lessons learned during the deployment of these two PMS phases, helping future initiatives, considering other energy companies, as well as companies from other industries. 
5

References

BEAMON, B. M. Measuring supply chain performance. International Journal of Operations and Production Management, [S.I.], v. 19, no. 3, p. 275-292, 1999.

Supply chain design and analysis: models and methods. International Journal of Production Economics, [S.I.], v. 55, no. 3, p. 281-294, 1998.

BITITCI, U. S. et al. Dynamics of performance measurement and organizational culture. International Journal of Operations \& Production Management, [S.I.], v. 26, no. 12, p. 1325-1350, 2006.

BITITCI, U. S.; TURNER, T.; BEGEMANN, C. Dynamics of performance measurement systems. International Journal of Operations \& Production Management, [S.I.], v. 20, no. 6, p. 692-704, 2000.

BOURNE, M. Implementation issues, hand book of performance measurement. [S.I.]: GEE Publishing Ltd., 2001.

BOURNE, M. et al. Designing, implementing and updating performance measurement systems. International Journal of Operations and Production Management, [S.I.], v. 20, no. 7, p. 754-771, 2000.

BOURNE, M. et al. The success and failure of performance measurement initiatives: Perceptions of participating managers. International Journal of Operations \& Production Management. [S.I.], v. 22, no. 11, p.12881310, 2002.

BOWERSOX, D. J.; CLOSS, D. J. Logistical management: the integrated supply chain process. [S.I.]: Hill International editions, 1996. $750 \mathrm{p}$.

BRAZ, R. G. F.; SCAVARDA, L. F.; MARTINS, R. A. Reviewing and improving performance measurement systems: An action research. International Journal of Production Economics, [S.I.], v. 133, no. 2, p. 751-760, 2011.

BURGESS, T. F.; ONG, T. S.; SHAW, N. E. Traditional or contemporary? The prevalence of performance measurement system types. International Journal of Productivity and Performance Management, [S.I.], v. 56, no. 7, p. 583-602, 2007.

CHENG, M. M.; LUCKETT, P. F.; MAHAMA, H. Effect of perceived conflict among multiple performance goals and goal difficulty on task performance. Accounting and Finance, [S.I.], v. 47, no. 2, p. 221-242, 2007. 
CRAWFORD, K. M.; COX, J. F. Designing performance measurement systems for just-in time operations. International Journal of Production Research, [S.I.], v. 28, no. 11, p. 2025-2036, 1990.

COUGHLAN, P.; COGHLAN, D. Action research for operations management. International Journal of Operations and Production Management, [S.I.], v. 22, no. 2, p. 220-240, 2002.

FERNANDEZ, N. S. et al. Diseño de sistemas de medición de desempeño de proveedores: experiencias de un caso de estudio. Produção, [S.I.], v. 22, n. 1, p. 43-57, 2012.

FORTUIN, L. Performance indicators: why, where and how? European Journal of Operational Research, [S.I.], v. 34, no. 1, p. 1-9, 1988.

FRANCO-SANTOS, $M$. et al. Towards a definition of a business performance measurement system. International Journal of Operations and Production Management, [S.I.], v. 27, no. 8, p. 784-801, 2007.

FRANCO-SANTOS, M.; LUCIANETTI, L.; BOURNE, M. Contemporary performance measurement systems: a review of their consequences and a framework for research. Management Accounting Research, [S.I.], v. 23, no. 2, p. 79-119, 2012.

GARENGO, P.; NUDURUPATI, S.; BITITCI, U. Understanding the relationship between PMS and MIS in SMEs: an organizational life cycle perspective. Computers in Industry, [S.I.], v. 58, no. 7, p. 677-686, 2007.

GLOBERSON, S. Issues in developing a performance criteria system for an organization. International Journal of Production Research, [S.I.], v. 23, no. 4, p. 639-646, 1985.

GLOBERSON, S.; DAROM, E. Comparison of three techniques for weighting importance of performance indications. In: FALL INDUSTRIAL ENGINEERING CONFERENCE, 1982, Cincinnati. Proceedings. Cincinnati: [s.n.], 1982.

GUMMESSON, E. Qualitative methods in management research. 2nd. ed. Thousand Oaks, California: Sage Publications, 2000. 249p.

HAAG, S.; CUMMINGS, M.; MCCUBBREY, D. J. Management information systems for the information age. Boston: McGraw-Hill Companies, Inc., 2002. 523p.

HUAN, S. H. et al. A review and analysis of supply chain operations reference (SCOR) model. International Journal of Supply Chain Management, [S.I.], v. 9, no. 1, p. 23-29, 2004. 
HWANG, $Y$ et al. The performance evaluation of SCOR sourcing process - The case study of Taiwan's TFT-LCD industry. International Journal of Production Economics, [S.I.], v. 115, no. 2, p. 411-423, 2008.

INTERNATIONAL ENERGY AGENCY. [S.I.], 2012. Available in: $<$ <ww.iea.org>. Consulted in: 2 Nov. 2012.

KAPLAN, R. S.; NORTON, D. P. The balanced scorecard: metrics that drive performance. Harvard Business Review, [S.I.], v. 70, no. 1, p. 7179, 1992.

KAPLAN, R. S.; NORTON, D. P. The balanced scorecard: translating strategy into action. Boston: Harvard Business Press, 1996. 322 p.

KENNERLEY, M., NEELY, A. A framework of the factors affecting the evolution of performance measurement systems. International Journal of Operations and Production Management, [S.I.], v. 22, no. 11, p. 12221245, 2002.

KRAKOVICS, F. et al. Defining and calibrating performance indicators of 4 $\mathrm{PL}$ in the chemical industry in Brazil. International Journal of Production Economics, [S.I.], v. 115, no. 2, p. 502-514, 2008.

LI, H.; WANG, D. Analyses of dynamic stakeholder views for CNPC. Journal of Sustainable Development, [S.I.], v. 1, no. 2, p. 32-38, 2008.

LOHMAN, C.; FORTUIN, L.; WOUTERS, M. Designing a performance measurement system design: a case study. European Journal of Operational Research, [S.I.], v. 156, no. 2, p. 267-286, 2004.

MANZANO, F. S. Supply chain practices in the petroleum downstream. Dissertation (Master Degree). Massachusetts Institute of Technology, 2005.

NEELY, A. D. et al. Performance measurement system design: a literature review and research agenda. International Journal of Operations and Production Management, [S.I.], v. 15, no. 4, p. 80-116, 1995.

NEELY, A. D. et al. Performance measurement system design: should process based approaches be adopted? International Journal of Production Economics, [S.I.], v. 46-47, p. 423-431, 1996.

NEELY, A. D. et al. Designing performance metrics: a structured approach. International Journal of Operations \& Production Management, [S.I.], v. 17, no. 11, p. 1131-1152, 1997.

NEELY, A. D. Business performance measurement: theory and practice. Cambridge, UK: Cambridge University Press, 2002. 369p. 
NEELY, A. D. Measuring business performance: why, what and how. London: The Economist and Profile Books Ltd., 1998. 224p.

NEELY, A. D.; ADAMS, C. The performance prism perspective. Journal of Cost Management, [S.I.], v. 15, no. 1, p. 7-15, 2001.

NEELY, A. D.; ADAMS, C.; CROWE, P. The performance prism in practice. Measuring Business Excellence, [S.I.], v. 5, no. 2, p. 6-12, 2001.

NEELY, A. D.; BOURNE, M. Why measurement initiatives fail. Measuring Business Excellence, [S.I.], v. 4, p. 3-7, 2000.

NEELY, A. D. et al. Getting the measure of your business. Cambridge, UK: Cambridge University Press, 2002. 143 p.

NEELY, A. et al. Performance measurement system design: developing and testing a process-based approach. International Journal of Operation \& Production Management, [S.I.], v. 20, no. 10, p. 1119-145, 2000.

NUDURUPATI, S. S.; ARSHAD, T.; TURNER, T. Performance measurement in the construction industry: an action case investigating manufacturing methodologies. Computers in Industry, [S.I.], v. 58, no. 7, p. 667-676, 2007.

NUDURUPATI, S. S.; BITITCI, U. S. Implementation of performance measurement systems: private and public sectors. Production Planning \& Control, [S.I.], v. 16, no. 2, p. 152-162, 2005.

NUDURUPATI, S. S. et al. State of the art literature review on performance measurement. Computers \& Industrial Engineering, [S.I.], v. 60, no. 2 , p. 279-290, 2011.

PARIDA, A.; KUMAR, U. Maintenance performance measurement (MPM): issues and challenges. Journal of Quality Maintenance Engineering, [S.I.], v. 12, no. 3, p. 239-251, 2006.

PARMENTER, D. Key performance indicators: developing, implementing and using winning KPIs. Hoboken, New Jersey: [s.n.], 2010. 295p.

PETROBRAS. Rio de Janeiro, 2011. Available in: <www.petrobras.com.br>. Consulted in: 09 Nov. 2011.

PLATTS, K. W. Characteristics of methodologies for manufacturing strategy formulation. Computer Integrated Manufacturing Systems, [S.I.], v. 3, no. 2, p. 93-99, 1994. 
RINALDI, F. S. B. Programa de controle de energias perigosas: estudo de caso em atividade de manutenção numa refinaria de petróleo. Dissertation (Master Degree) - Universidade Federal Fluminense, Niterói, 2008.

ROCKART, J. F. Chief executives define their own data needs. Harvard Business Review, [S.I.], v. 57, no. 2, p. 81-93, 1979.

SHEPHERD, C.; GUNTER, H., Measuring supply chain performance: current research and future directions. International Journal of Productivity and Performance Management, [S.I.], v. 55, no. 3-4, p. 242-258, 2006.

SHNEIDERMAN, B. Tree visualization with treemaps: a 2-D space-filling approach. ACM Transactions on Graphics, [S.I.], v. 11, no. 1, p. 92-99, 1992.

STEWART, G. Supply-chain operations reference model (SCOR): the first cross-industry framework for integrated supply-chain management. Logistics Information Management, [S.I.], v. 10, no. 2, p. 62-67, 1997.

SUPPLY CHAIN COUNCIL. Supply-chain operations reference: model: version 9.0. Pittsburgh, 2008.

SUPLY CHAIN COUNCIL. Pittsburgh, 2012. Available in: <http://supplychain.org/>. Consulted in: 15 Dec. 2012.

What is SCOR? Pittsburgh, 2012a. Available in: <http://supplychain.org/scor>. Consulted in: 18 Dec. 2012.

TANGEN, S. Performance measurement: from philosophy to practice. International. Journal of Productivity and Performance Management, [S.I.], v. 53, no. 8, p. 726-737, 2004.

WANG, G. Product-driven supply chain selection using integrated multicriteria decision-making methodology. International Journal of Production Economics, [S.I.], v. 1, no. 91, p. 1-15, 2004.

WISNER, J. D.; FAWCETT, S. E. Link firm strategy to operating decisions through performance measurement. Production and Inventory Management Journal, [S.I.], v. 32, no. 3, p. 5-11, 1991.

TRANSPETRO. Rio de Janeiro, 2011. Available in: <www.transpetro.com.br>. Consulted in: 11 Nov. 2011.

YIGITBASIOGLU, O. M.; VELCU, O. A review of dashboards in performance management: implications for design and research. International Journal of Accounting Information Systems, [S.I.], v. 13, p. 41-59, 2012. 


\section{6 Appendix}

Figure 14 shows a SMDO screen with the metrics from Final Products Inventory Management, inside the cluster Assets Management, evidencing the two-level hierarchical arrangement of the metrics. Figure 15 illustrates how the use of the treemap helps prioritizing deviations in metrics parcels.

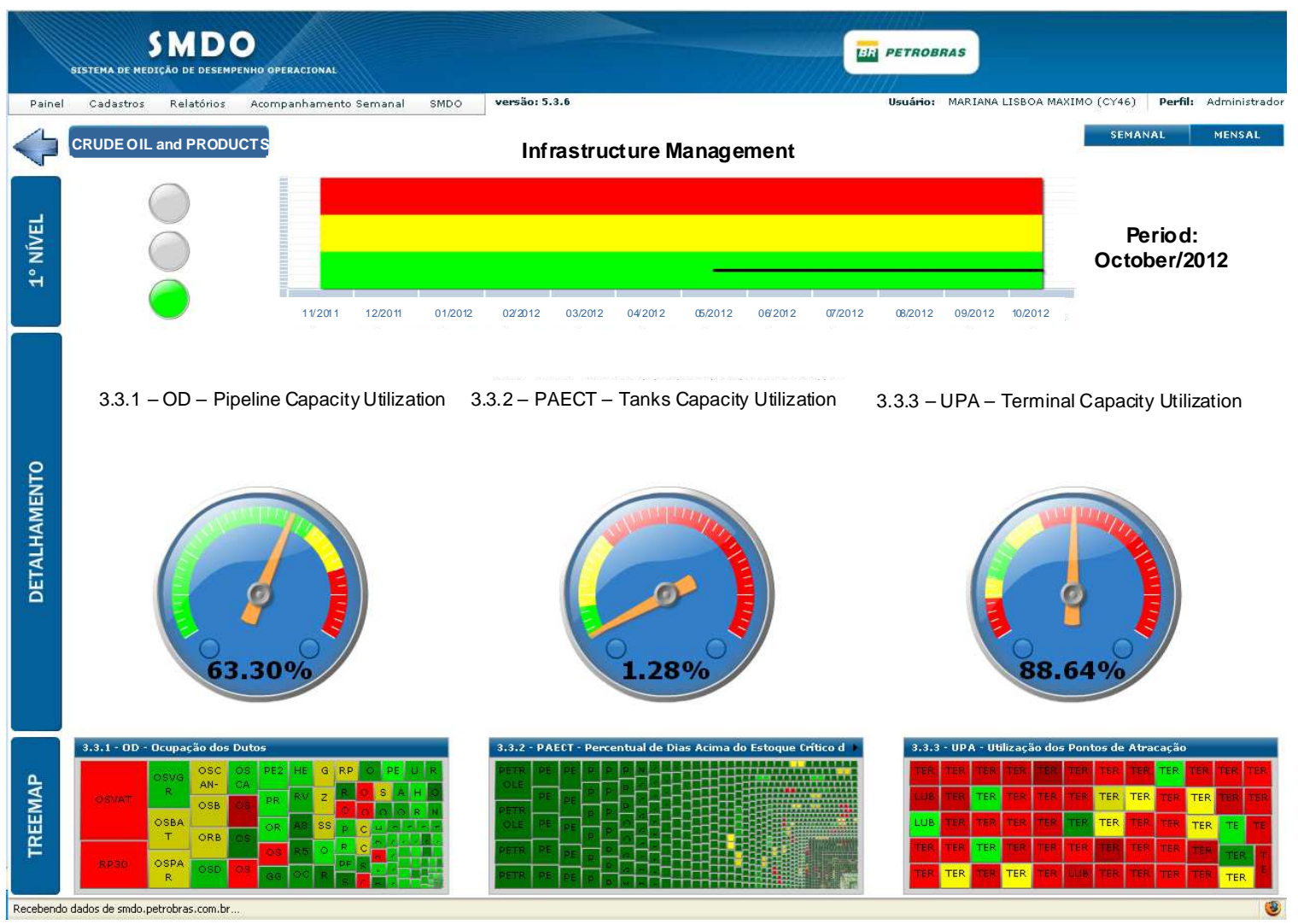

Figure 14 - SMDO screen of Assets Management cluster, Infrastructure Management division

Source: Petrobras SMDO system. 


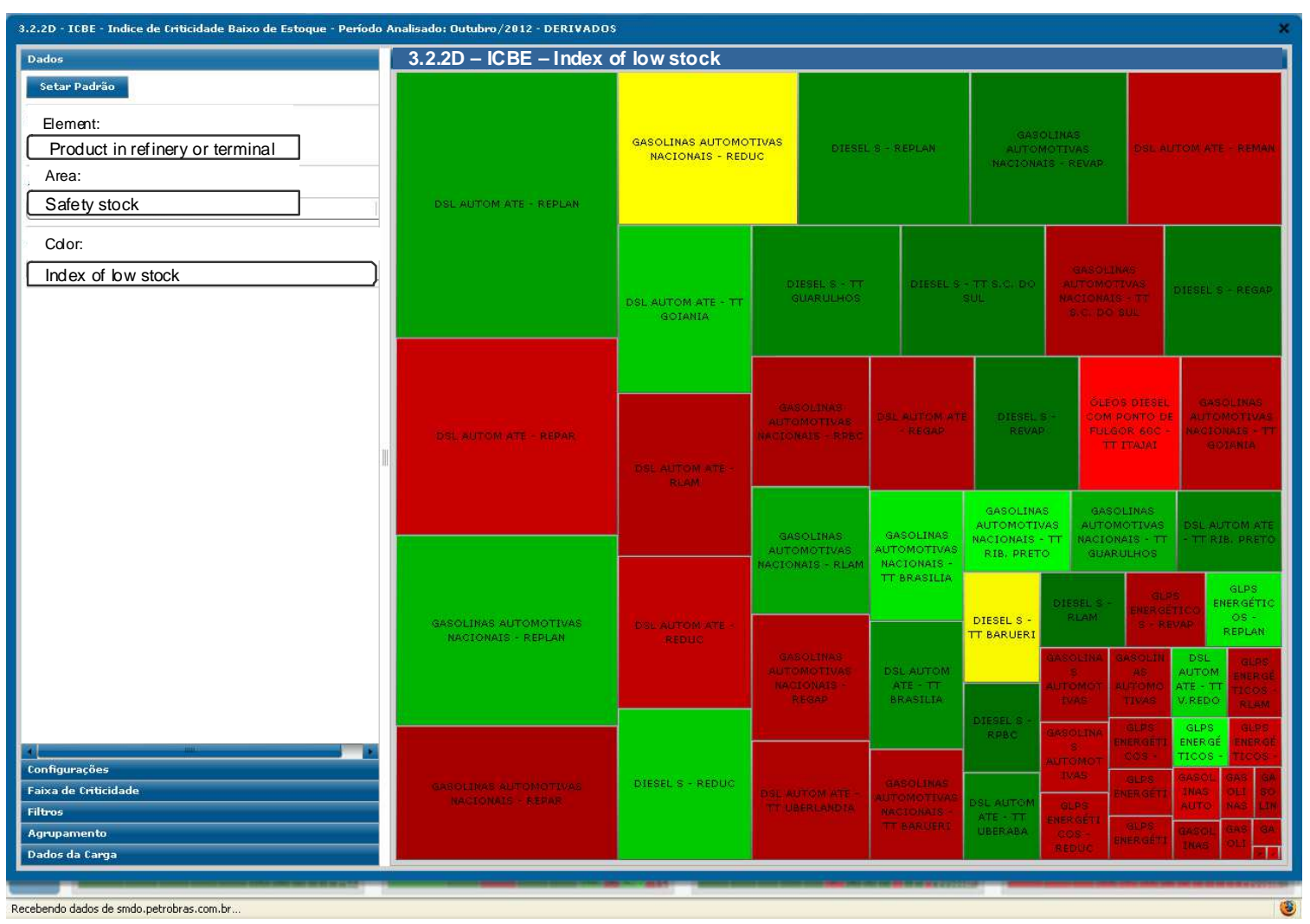

Figure 15 - Example of Treemap - technological tool to better visualize deviations in a performance metric

Source: Petrobras SMDO system. 